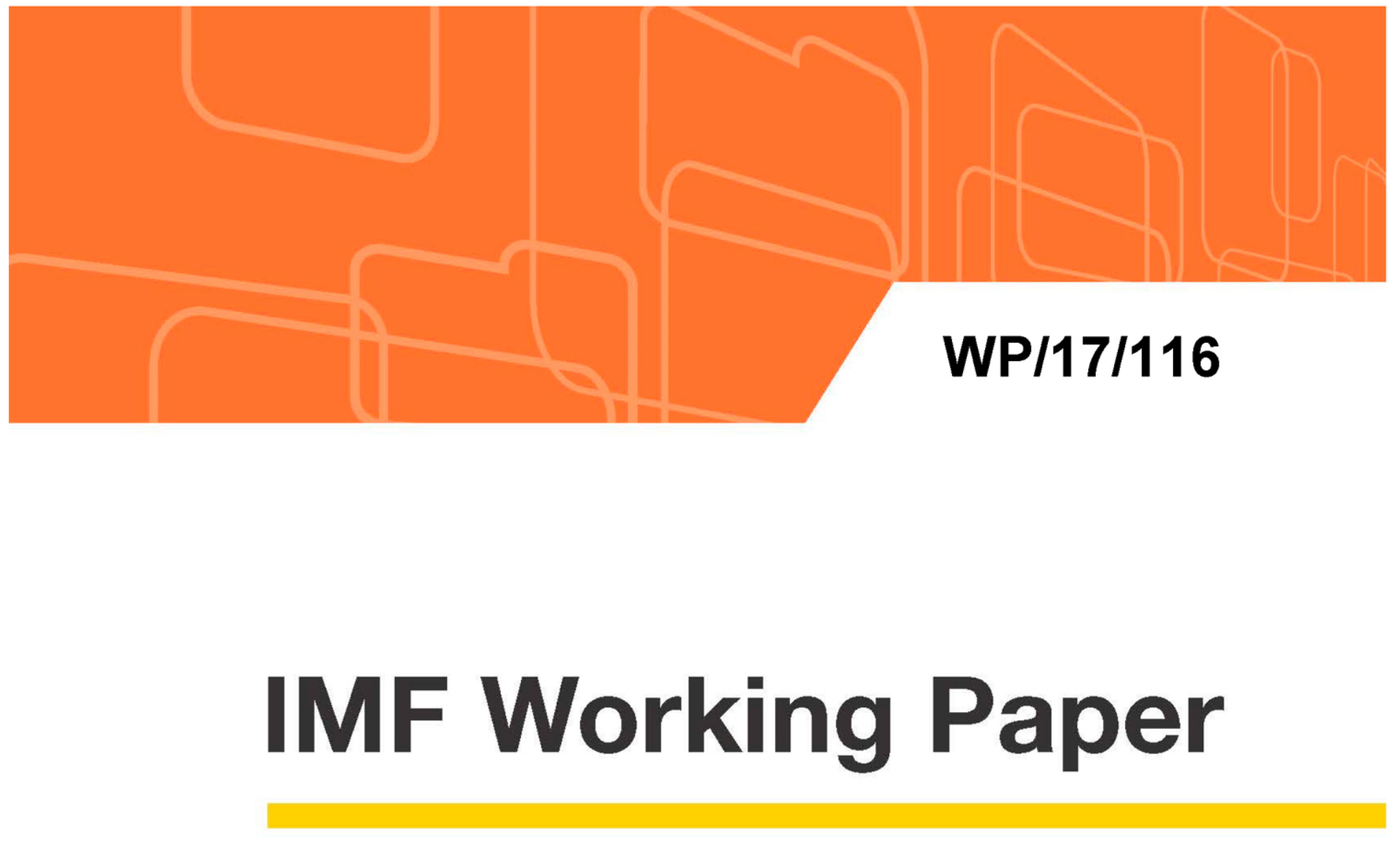

\title{
Bank Solvency and Funding Cost: New Data and New Results
}

by Stefan W. Schmitz, Michael Sigmund, and Laura Valderrama

IMF Working Papers describe research in progress by the author(s) and are published to elicit comments and to encourage debate. The views expressed in IMF Working Papers are those of the author(s) and do not necessarily represent the views of the IMF, its Executive Board, or IMF management. 


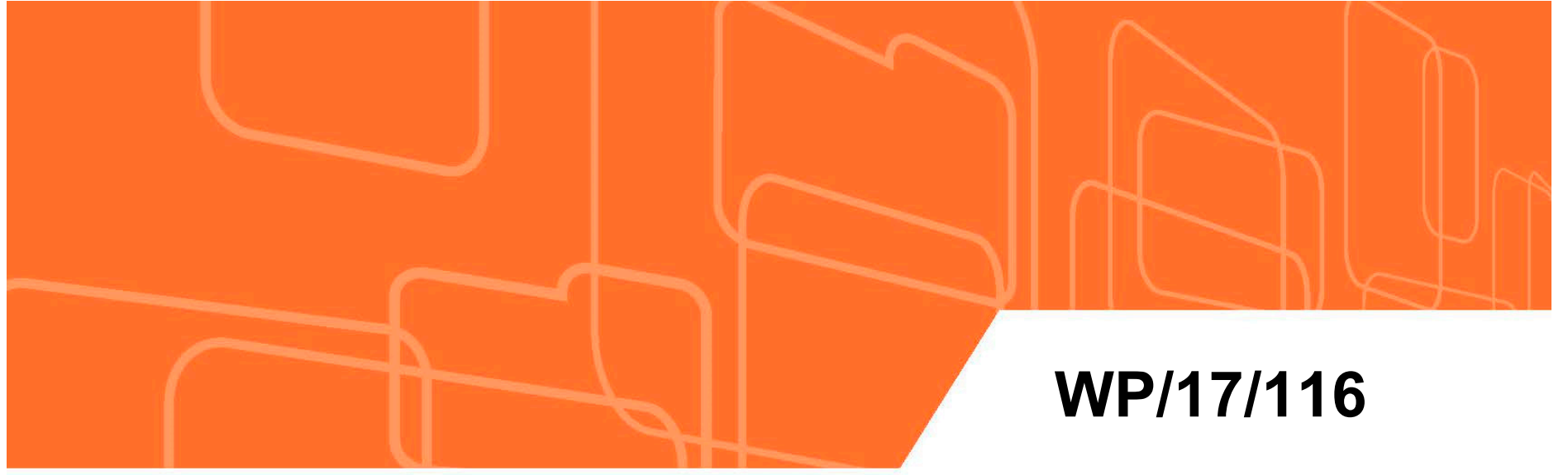

\section{IMF Working Paper}

\section{Bank Solvency and Funding Cost: New Data and New Results}

by Stefan W. Schmitz, Michael Sigmund, and Laura Valderrama

IMF Working Papers describe research in progress by the author(s) and are published to elicit comments and to encourage debate. The views expressed in IMF Working Papers are those of the author(s) and do not necessarily represent the views of the IMF, its Executive Board, or IMF management. 


\title{
IMF Working Paper
}

Monetary and Capital Markets Department

\author{
Bank Solvency and Funding Cost: New Data and New Results \\ Prepared by Stefan Schmitz, Michael Sigmund, and Laura Valderrama \\ Authorized for distribution by Udaibir S. Das
}

May 2017

\begin{abstract}
IMF Working Papers describe research in progress by the author(s) and are published to elicit comments and to encourage debate. The views expressed in IMF Working Papers are those of the author(s) and do not necessarily represent the views of the IMF, its Executive Board, or IMF management.
\end{abstract}

\begin{abstract}
This paper presents new evidence on the empirical relationship between bank solvency and funding costs. Building on a newly constructed dataset drawing on supervisory data for 54 large banks from six advanced countries over 2004-2013, we use a simultaneous equation approach to estimate the contemporaneous interaction between solvency and liquidity. Our results show that liquidity and solvency interactions can be more material than suggested by the existing empirical literature. A $100 \mathrm{bps}$ increase in regulatory capital ratios is associated with a decrease of bank funding costs of about $105 \mathrm{bps}$. A $100 \mathrm{bps}$ increase in funding costs reduces regulatory capital buffers by 32 bps. We also find evidence of non-linear effects between solvency and funding costs. Understanding the impact of solvency on funding costs is particularly relevant for stress testing. Our analysis suggests that neglecting the dynamic features of the solvency-liquidity nexus in the 2014 EU-wide stress test could have led to a significant underestimation of the impact of stress on bank capital ratios.
\end{abstract}

JEL Classification Numbers: G20, G30

Keywords: Solvency, funding cost, stress testing.

Authors’ E-Mail Addresses: stefan.schmitz@oenb.at, Michael.Sigmund@oenb.at, and LValderrama@imf.org 


\section{Contents}

I. Introduction

II. Related Literature $\underline{6}$

III. The Relation Between Solvency Risk and Funding Costs $\underline{8}$

A. Construction of a New Dataset 9

B. A Simultaneous Equation Approach $\underline{15}$

IV. Estimation Results $\underline{16}$

V. Robustness Checks $\underline{20}$

A. Introducing a Market-based Measure of Bank Solvency $\underline{20}$

B. Introducing a Measure of Liquidity Risk $\underline{21}$

VI. Application to Stress Testing $\underline{22}$

VII. Summary and Conclusions $\underline{25}$

References $\underline{40}$

Figures

1. Cross-sectional Distribution of Bank Solvency and Funding Costs

2. Evolution of Bank Solvency and Funding Costs $\underline{37}$

3. Decomposition of Impact on CET1-2014 EBA Stress Test $\underline{38}$

Tables

1. Data Coverage $2 \frac{23}{24}$

2. Summary Statistics of the Dependent and Independent Variables

$\underline{24}$

3. Cross-Correlation Matrix of the Dependent and Independent Variables 25

4. Bank Regulatory Capital and Funding Costs $\underline{26}$

5. Test Results for Bank Regulatory Capital and Funding Costs 27

6. Market-Based Bank Solvency and Funding Costs $\underline{28}$

7. Test Results for Market-Based Bank Solvency and Funding Costs $\underline{29}$

8. Bank Regulatory Capital and Funding Costs (Controlling for Liquidity Risk) $\underline{30}$

9. Test Results for Bank Regulatory Capital and Funding Costs (Controlling for Liquidity Risk)

10. Market-Based Bank Solvency and Funding Costs (Controlling for Liquidity Risk) $\underline{31}$

11. Test Results for Market-Based Bank Solvency and Funding Costs (Controlling for Liquidity Risk)

12. Bank Regulatory Capital and Funding Costs (OLS Estimation) $\underline{33}$

13. Market-Based Bank Solvency and Funding Costs (OLS Estimation) $\underline{34}$

14. Impact of Bank Solvency and Funding Cost Interaction-2014 EBA Stress Test $\underline{35}$

$\underline{36}$




\section{INTRODUCTION}

The global financial crisis appears to have been a liquidity crisis, not just a solvency crisis. ${ }^{1}$ Yet the failure to adequately model interlinkages and the nexus between solvency risk and liquidity risk led to a dramatic underestimation of risks. Liquidity risk manifests primarily through a liquidity crunch as firms' access to funding markets is impaired, or a pricing crunch, as lenders are unwilling to lend unless they receive much higher spreads. We extract funding liquidity risk from observing the costs that banks are required to pay to secure market liquidity. A sudden increase in bank funding costs can have an adverse impact on financial stability through the depletion of banks' capital buffers. To preserve financial stability, it is important to assess banks' vulnerability to changes in funding costs. The reason is twofold. First, to the extent funding costs reflect counterparty credit risk, it is of particular interest for supervisors to determine the level of capital buffers that should be held to keep funding costs at bay if and when market conditions deteriorate. Second, funding costs are linked not only to banks' initial capital position but also they determine their capital position going forward, paving the way for adverse dynamics. The magnitude of this effect is likely to depend on the bank's behavioral reaction to rising funding costs. On the one hand, it may react by setting higher lending rates to its borrowers. Yet this action reduces the bank's market share and its franchise value. On the other hand, the bank might not be able to passthrough additional funding costs to new lending so its internal capital generation capacity is reduced. Even if some pass-through is possible, the erosion of profits is likely to be substantial given the shorter time to repricing of liabilities relative to assets with the margin impact on the carrying values of assets outweighing that of new asset generation. ${ }^{2}$

The dynamics of adverse economic conditions on banks' capital position can be examined through a stress testing exercise. Typically, bank stress tests measure the resilience of banks to hypothetical adverse scenarios. While stressed conditions capture a deterioration of banks' economic conditions such as a severe recession and a sharp correction in asset prices, they do not reflect the gradual increase in funding costs that banks experience as their capital buffers are depleted. The analysis presented in this paper suggests that stress test models that do not consider the dynamics between solvency and funding costs are likely to underestimate the impact of stress on bank solvency and financial stability. ${ }^{3}$ First, higher funding costs erode bank capital buffers in the short-term due to the back-book effect. ${ }^{4}$ Second, capital buffers

\footnotetext{
${ }^{1}$ Shleifer. A., and Vishny, R. (2011) argue that liquidity problems caused by fire sales contributed to the depth and propagation of the crisis.

${ }^{2}$ This conjecture also holds, if the share of variable rate loans is high. The variable rates usually vary with market rates (e.g., three months LIBOR) plus a fixed margin. This does not allow banks to adjust variable rates to bank specific increases in funding costs. Similarly, interest rate hedges insure against movements in market rate, but not in bank specific mark-ups on market rates.

${ }^{3}$ With the caveat that, if banks that anticipate holding riskier assets also post higher capital ratios, capital ratios would not reflect balance sheet strength but changes in riskiness of underlying assets. This would imply that we should not be able to observe a negative relationship between capital ratios and funding costs.

${ }^{4}$ Kitamura et al (2015) find that the median value of one-year ahead pass-through for Japanese banks is 0.18 .
} 
are further depleted in the long-term as risk sensitive investors' demand for a higher compensation to bear risk, sets off adverse dynamics and lengthens the persistence of funding shocks.

This paper aims to answer two questions. First, what is the magnitude of the interaction between funding costs and solvency? Second, how can the estimated effects be used for stress testing purposes? To address these two issues, we construct a new dataset and test for the importance of the two-way interaction between funding conditions and bank solvency. Our results lend support to the joint determination of funding costs and bank solvency. We also provide some evidence of non-linear interactions between funding costs and solvency risk, and find that this relationship has not changed significantly during the crisis.

While these results are somewhat consistent with the literature on bank solvency and funding costs, we extend the literature in two directions. First, we build a unique dataset consisting of supervisory reporting data of 54 large banks over 2004-2013 5 shared across supervisory agencies from six countries. ${ }^{6}$ We check that the data is of higher quality than the publicly available sources used in other studies. Second, we focus on the endogenous determination of solvency and funding costs, contrary to the approach taken in most studies which investigate funding cost drivers. To this end, we study the interaction between solvency and liquidity using a simultaneous equation approach based on a set of exogenous instrumental variables, rather than using lagged values of endogenous variables as under a VAR specification. This is motivated by our concern that, given the endogeneity of capital and funding costs discussed above, an OLS-based regression is likely to yield biased coefficients. A priori, the direction of the bias is uncertain. On the one hand, one might argue that banks perceived by bondholders to be riskier might face both higher funding costs and hence seek to maintain higher capital ratios to address market's perceived risk. And if this perception is unobserved in the empirical analysis, then OLS estimates are likely to underestimate the negative impact of funding costs on solvency. On the other hand, OLS estimates can overstate this negative relationship if positive shocks to solvency, which are likely to also affect funding costs, remain unobserved. Concretely, if markets expect that a strong bank will become safer by raising its capital ratio, current funding costs might decline more than warranted by its current capital position. But if this expectation is unobserved, then OLS estimates will overstate the negative relationship between solvency and funding costs. Our results provide evidence that OLS underestimates the impact of capital on funding costs. Whereas a multivariate OLS-based panel regression on our dataset yields a positive relationship between banks' capital position and funding costs, our simultaneous equation-based analysis suggests a large negative impact of capital on the cost of funding.

\footnotetext{
${ }^{5}$ Since not all of these banks are publicly traded, we use a restricted sample for some econometric specifications.

${ }^{6}$ Due to the sensitivity of the data, strict confidentiality arrangements were in place.
} 
Our results suggest more sizeable effects than those found in the literature. We find that a $100 \mathrm{bps}$ increase in regulatory capital is associated with a 105 bps decrease in funding costs, which is a large effect relative to the existing literature, where the effect tends to be smaller, at an average of 50 basis points. ${ }^{7}$ We illustrate an application of our empirical work to inform stress testing projections of bank capital ratios under stressed conditions, using the 2014 EUwide stress test exercise.

The rest of the paper is structured as follows. Section II reviews the existing literature. Section III introduces the new dataset and presents the econometric approach. Section IV shows the main findings on the interaction between regulatory capital and funding costs. Section V explores the robustness of the results to a market-based definition of bank solvency, and to banks' bearing capacity for liquidity risk. Section VI illustrates the dynamic impact of the solvency-funding interaction in a stress testing framework. Section VII concludes with some policy implications.

\section{RELATED LITERATURE}

This paper is related to the empirical literature on the relationship between bank solvency and funding conditions, where funding conditions are defined in terms of funding costs rather than in relation to bank access to funding markets. ${ }^{8}$ There are two main strands of literature: a broader set of papers seeking to explain the effect of banks' balance sheet fundamentals on funding costs, and an emerging literature examining the two-way interaction between bank solvency and the cost of funding.

Within the first strand, one set of papers base their estimates on a multivariate panel estimation of large banks. Annaert et al. (2010) find that the interaction between solvency and funding costs is indeed significant in a sample of 31 large euro area banks over the precrisis period from 2004 through October 2008. A one percentage point drop in weekly bank stock returns (associated with higher implied market-based leverage), is associated with a 64 basis points rise in a bank's CDS spread. Similarly, Hasan et al. (2016) show that solvency has significant impact on bank funding costs using a sample of 161 global banks from 23 countries over 2001-2011. An increase of one percentage point in market-based leverage raises CDS spreads by an average of 101 basis points. This effect is slightly more pronounced after 2007 when the sensitivity of the coefficient increases to 103 basis points. In addition, they also include costs of funds (proxied by interest expense over total assets) as an explanatory variable which turns out to be significant. However, this seems to point to an endogeneity problem as CDS spreads and funding costs are expected to be jointly determined. Likewise, Aymanns et al. (2016) examine the sensitivity of bank funding costs

\footnotetext{
${ }^{7}$ A recent study by Aymanns et al (2016) finds that a solvency shock of 500 bps lead to an average increase in interbank funding cost of about $20 \mathrm{bps}$, with a peak impact of $40 \mathrm{bps}$ in 2007.

${ }^{8}$ Whereas our baseline specification focuses on the cost of bank funding, we also conduct robustness checks to include stress conditions on funding volumes.
} 
to bank solvency drawing on the FDIC call report covering 10,000 banks over the period 1993-2013. They perform a panel estimation to quantify the impact of changes in bank fundamentals on yearly balance-sheet measures of banks' funding costs. The latter are captured by either wholesale funding (interest rate expenses on feds funds) or average funding costs (total interest expense over total liabilities). Their independent variables are bank fundamentals clustered by factor analysis. The constituent variables stem from four groups, solvency, liquidity, asset quality and profitability. They find a larger negative coefficient of bank solvency on wholesale funding costs, pointing at the higher credit risk sensitivity of wholesale investors relative to depositors. Their results suggest that the sensitivity of funding cost to bank capital is larger in bad times. Whereas the average effect is typically small, with a solvency shock of five percentage points leading to an average increase in interbank funding cost of about 20 basis points, this effect rises to 40 basis points in 2007 when wholesale funding providers' sensitivity to solvency risk reached its peak. The analysis also shows that the relationship between funding cost and solvency is non-linear, with higher sensitivity of funding cost at lower levels of bank solvency. Afonso et al. (2011) conduct an event study around Lehman Brothers' bankruptcy using transaction-level data containing all transfers by U.S. banking institutions through Fedwire. They find that the worst performing large banks access the federal funds market least, whereas the small banks access the market at an increase in funding spreads of over 96 bps. Acharya and Mora (2015) show that banks' vulnerability to liquidity risk, defined as banks' exposure to liquidity demand risk due to credit line drawdowns and materializing in higher deposit rates, is greater in magnitude for the class of banks with greater solvency problems proxied by lower asset quality. The study is conducted on a panel of 7,000 U.S. banks over the 2007-2009 financial crisis.

A different estimation method is applied by Babihuga and Spaltro (2014). In the context of a panel error correction model (PECM), they estimate the long- and short-run effects of bankspecific and macro variables on funding costs using a panel of 52 banks in 14 advanced economies over 2001-2012. In the long-run, a one percentage point increase in bank regulatory capital reduces funding costs by 26 basis points, though this relationship is somewhat reversed in the short-term, wherein an increase in bank capital is associated to rising bank funding costs two quarters ahead. Gray et al. (2012) use a contingent claims analysis (CCA) approach to compute a fair value credit spread (FVCDS) as a proxy of bank funding cost using a Merton-based approach. Combining FVCDS with an implied marketbased capital ratio the authors find a non-linear relationship between funding costs and bank capital. Under the baseline scenario, banks' weighted average EDF rises steadily at an accumulated pace of 75 percent by the end of the stress testing horizon. This is mapped to an equivalent 75 percent rise in FVCDS. Yet, under the adverse scenario, the projected accumulated increase of 150 percent in the EDF measure is linked to a larger rise in FVCDS revealing a non-linear relationship between market-based solvency and funding costs.

Within the second strand of the literature, Pierret (2014) uses fixed-effect panel vector autoregressive (PVAR) regressions to model the nexus between solvency and liquidity risk of 
banks in a set of 49 U.S. banks examined over 2000 to 2013. The main result suggests and asymmetric relationship: higher solvency risk, measured by the expected capital shortfall SRISK ${ }^{9}$ defined by Acharya et al. $(2010,2012)$ and Brownlees and Engle (2011), limits the access of the firm to short-term funding. Yet a firm with more liquidity risk exposure, proxied by short-term debt, has a higher risk of insolvency in a crisis. Specifically, a unit increase in the expected capital shortfall ratio reduces its short-term debt ratio by 1.1 percentage points, suggesting that riskier banks find their access to wholesale markets limited. On the other hand, banks posting a one percent increase in short-term debt see their expected capital shortfall ratio increase by 0.9 percentage points suggesting that banks funded with more short-term debt face higher solvency risk. Our paper is more closely related to Distinguin et al. (2013), which uses a simultaneous equation approach to study the endogenous interaction between solvency and funding volumes on a panel of 870 United States and European publicly traded commercial banks over 2000-2006. For the solvency part, they use regulatory capital ratios as proxy. On the funding side, they focus on the inverse of the NSFR and a so-called liquidity creation indicator. They show that banks creating more liquidity have lower regulatory capital levels, and banks with lower capital ratios post higher measures of liquidity transformation. Our approach differs insofar as we focus on funding costs rather than on funding volumes, and in that we investigate the relationship between solvency and funding costs on a newly constructed dataset drawing on supervisory returns. We also calibrate the impact of incorporating the solvency-funding costs interaction on banks' resilience using the 2014 EBA stress testing framework.

\section{The Relation Between SolvenCy Risk AND Funding Costs}

To assess the resilience of financial institutions to adverse shocks, it is important to understand the interaction between solvency and funding costs. This is particularly relevant in the design of stress tests where different types of shocks can affect regulatory ratios for capital and liquidity simultaneously. ${ }^{10}$

A sharp rise in bank funding costs is likely to have an adverse effect on bank capital by eroding net interest income. Yet the channels through which funding costs affect profits are not straightforward. A bank may react by absorbing higher cost of funding thus reducing its profitability. Alternatively, the bank may try to pass on the increased cost to customers by charging high lending rates on new lending. This action might also erode profitability as liabilities reprice faster than assets and the demand for new lending is depressed, compressing the income base. ${ }^{11}$ The effect of bank capital on funding costs is also complex

\footnotetext{
${ }^{9}$ The SRISK measure is defined as the difference between the regulatory capital ratio applied to the expected value of assets in the event of a financial crisis and the expected market value of capital.

${ }^{10}$ Cetina (2015) discusses the channels through which shocks can impact regulatory solvency and liquidity ratios simultaneously.

${ }^{11}$ Bank of England (2014) provides a thorough discussion of the effect of a shock to bank funding costs on bank capital and financial stability.
} 
due to the highly non-linear relation between bank asset value and solvency risk due to the short-put option embedded in bank assets. Moreover, the compensation required by investors to bear solvency risk depends on scarcity effects from compressed bond issuance under stress, on investors' funding liquidity, and on systematic risk factors. This section uses a reduced-form approach and a broad set of controls as a useful starting point for the calibration of the impact of solvency stress on bank funding costs in supervisory stress tests.

\section{A. Construction of a New Dataset}

The variables included in the new dataset were collected specifically for the purpose of estimating the simultaneous interdependence of bank solvency and funding costs. The data consist of an unbalanced panel of 54 large banks from six countries that cover the period from 2004Q4 to 2013Q4. With 33 banks in the sample, the United States is the largest contributor to the sample. The sample also includes six Austrian, six Canadian, six Dutch, and three Nordic banks. The bank data were shared among regulatory agencies of the respective countries under strict confidentiality protocols and went through careful data filtering and quality checks. ${ }^{12}$

Measuring the solvency-funding cost nexus is complicated due to the different frequencies of regulatory data for funding costs and solvency. The frequency of the former is usually much higher (up to daily) than for the latter (usually quarterly). The empirical analysis focuses on quarterly data. Another challenge for the analysis is posed by the choice of proxies to capture funding costs and solvency risk.

Banks can refinance their operations in different funding markets by tapping retail deposits, unsecured wholesale funding (including unsecured corporate deposits as well as funds sources from money markets and bond markets), and secured funding (including repos, securities lending, and securitization). We proxy funding costs by the marginal cost of longterm unsecured wholesale funding. We use the five-year senior single name CDS spread for each bank in the sample. This is a reasonable proxy as the sample consists of large international banks where CDS liquidity is usually higher than for the average bank. Also, CDS spreads are market-implied risk-neutral probabilities, which are obtained under the assumption that investors are risk-neutral and desire no risk premia, and thus are immune to shifts in risk aversion sentiment.

Alternatively, we could use secondary market spreads on active bonds to approximate the cost of wholesale funding. However, time series analysis drawing on is variable is challenging as bond features change over time (e.g., face value, maturity, covenants). In contrast, time series data for CDS spreads are ready available and do not suffer from changes in the maturity structure of a bank's debt.

\footnotetext{
${ }^{12}$ Supervisory data is based on reported regulatory balance sheets and include confidential supervisory information gathered through supervisory processes.
} 
Another option is to use a measure of short-term wholesale funding costs. We prefer using the five-year fair value CDS spreads and the reason is threefold. First, bank specific data on short-term funding costs often reflects quoted prices rather than actual transaction prices. Second, variations in counterparty risk perception often lead to a volume reaction (i.e., shortening of tenors or a reduction of lines) rather than to significantly higher rates. Third, unconventional monetary policy (UMP), including full allotment and QE, limited the variation and information content of short-term market rates as a proxy for banks' marginal funding costs, although we expect the impact of UMP in our analysis to be rather limited. The measures are available to all banks in the respective economies; thus, we do not expect it to systematically affect the variation of CDS spreads across banks. Data on individual emergency liquidity assistance (ELA) could reduce the bank's CDS and affect our estimates. Though central banks try to keep ELA confidential, we are quite confident that no bank in the sample received ELA.

There are several caveats associated with the use of CDS as a measure of funding costs. First, market liquidity in CDS markets might be limited for specific banks in the sample (e.g., for some of the smaller European banks). To account for this unobserved heterogeneity, we use bank-specific fixed effects. Second, CDS spreads may not be representative of bank funding costs under stress if the bank is shut out of the funding market. We take the view, however, that even under this extreme scenario, they signal effectively the marginal shadow cost of funding and thus affect a bank's internal fund transfer pricing. Third, CDS spreads may reflect counterparty concerns over the issuer of credit protection. Yet, in line with the aforementioned literature, we do not expect this to systematically bias CDS spreads over the sample period. In any case, to measure effectively funding costs, the actual funding structure of each bank should be considered and the cost of alternative funding sources calibrated. ${ }^{13}$

Turning to solvency risk, the link between equity and default probability has been widely established in structural models of firms' default (Merton, 1974), tested empirically (Ericsson et al., 2009), and used as a framework to calibrate Basel III regulatory capital. This motivates our choice of solvency risk, i.e., core tier 1 ratio (CT1), which reflects high quality regulatory capital relative to risk weighted assets. ${ }^{14}$ Yet the relationship between solvency risk and capital structure is somewhat more complex in banks relative to corporate firms. First, most bank debt is short-term which introduces liquidity risk into solvency risk. We address this concern by introducing bank liquidity buffers as a control variable. Second, bank regulation and supervision, deposit guarantee schemes, and implicit government guarantees (including the underpriced liquidity insurance via access to central bank emergency liquidity assistance

\footnotetext{
${ }^{13}$ The case studies discussed in BCBS (2013a) and BCBS (2013b) provide useful illustrations of this issue.

${ }^{14}$ The instruments included in CT1 are well comparable across jurisdictions; while those included in Tier 1 and Tier 2 comprise of instruments that are more country-specific. Core equity tier 1 (CET1) would be even more comparable across jurisdictions, but was introduced only recently in Basel III. Thus, CET1 data is not available for our sample period.
} 
for illiquid and often insolvent banks) suggest that the default boundaries as well as explanatory variables for bank CDS spreads also differ from that of non-financial companies. ${ }^{15}$ This is a consequence of the perceived public good characteristics of financial stability and the ensuing specific regulatory framework banks operate in. We capture implicit government guarantees for bank debt by including a proxy for government credit risk reflected in its sovereign CDS spreads, as well as by considering a bank's credit rating from $\mathrm{S} \& \mathrm{P}$ with the uplift based on government support. We transform the standard rating scale into a 1 (best rating or AAA) to 24 (worst rating) numerical scale (S\&P). Third, the distance to default is typically higher for banks than for non-financial firms because banks not only have to maintain minimum regulatory capital ratios but also because the required capital buffer is commensurate with the underlying volatility of assets. In theory that should ensure that the recovery rate of a failing bank is higher than for non-bank financial companies. Lastly, the Merton model relies on observed values of asset volatility. Yet as attested during the global financial crisis, the underlying bank asset volatility is unobservable and can quickly rise if bank asset values fall, which implies that the default barrier can be reached faster than implied by the Merton approach. To capture the risk of underlying assets and bank capacity to generate future profits we include asset quality and net interest income as regressors. In sum, there are strong arguments to suggest that the model of bank solvency is more complex than that of non-financial companies and a broader range of variables needs to be considered. To address the robustness of our results to different measures of bank resilience, we re-run the estimation using a market-based measure of bank default probability over five years, namely the expected default frequency (EDF) estimated by Moody's Credit Edge. ${ }^{16}$

We consider a wide range of bank specific variables as potential determinants of bank solvency and funding cost. We use two balance sheet variables which play key roles in solvency stress tests, i.e., loan loss provisions in percent of total assets (LLP) as a measure of asset quality, and net income in percent of total assets (NI) as a proxy for banks' return on assets and its organic recapitalisation capacity. Provisions have a direct impact on bank solvency through their effect on risk weighted assets. We are aware, however, of the shortcomings of this proxy. Banks have some leeway in determining loan loss provisions and can use it as a signalling device to the market, to accommodate regulators, to smooth earnings over time and for tax optimisation purposes. In addition, regulations and accounting rules have an impact on the level and timing of the recognition of changes in banks' capital adequacy.$^{17}$ This recognition is part of the rationale for considering, as an alternative to the supervisory solvency ratio in Section IV, the EDF measure, which is more market oriented. We also control for banks' resilience to liquidity shocks, which is monitored regularly by the

\footnotetext{
${ }^{15}$ See BCBS (2013a).

${ }^{16}$ Moody's uses a Merton-based model whereby the equity of a firm is analogous to holding a call option on the firm's assets and the required debt payment serves as the option's strike price. See Sun (2012) for further discussion of Moody's methodology.

${ }^{17}$ See (BCBS 2015a) for further details.
} 
regulatory authorities. We define liquidity risk (LiRisk) as a bank's liquidity risk exposure measured by its short-term wholesale debt (liabilities with a remaining maturity of less than three months) over its liquidity risk bearing capacity defined as the stock of liquid assets (cash and central bank excess reserves, sovereign debt with risk-weights of 0 and 20 percent). A higher ratio implies that the bank is exposed to higher roll-over risk. Also, wholesale funding is more credit sensitive and is likely to react more strongly to an erosion of bank capital buffers. At the same time, banks might profit from maturity transformation to a larger extent by funding a larger share of long-term assets with short-term wholesale funding, supporting bank profitability and easing credit risk. The sign of the liquidity risk coefficient is likely to depend on the initial capital position of banks.

The cost of funding also depends on investors' confidence in banks' funding instruments and in changes to macroeconomic conditions. We address the potential regime shift around the outbreak of the global financial crises in 2008 by using the following control variables. First, we include a nonbank, non-country specific variable that proxies for market sentiment in the interbank market. The LIBOR-OIS spread is a widely-used gauge for tensions in money markets. It tends to be high in times of stress and low otherwise. Second, we control for substantial changes in monetary policies and for the introduction of unconventional measures which were designed to dampen bank funding costs by using the overnight index swap (OIS) as a proxy for the monetary policy stance at the global level. While the specifics of unconventional measures differ between the various currency areas in our sample and the reliance of individual banks on these central bank measures differ, this information is not publicly available in a systematic manner. In the model, we allow for bank specific fixed effects to capture such unobservable differences. Third, we include a market measure of volatility to capture global risk aversion. ${ }^{18}$ This is motivated by evidence that a common systemic risk factor can reduce the discrepancy between modelled and actual returns for corporate bondholders (Chen et al, 2009). We proxy global risk aversion by the VIX index. This is a reasonable assumption as the sample of banks includes internationally active banks holding international asset portfolios and raising funding from international creditors. Global risk attitude can have an impact on bank funding costs, especially for hedging products such as credit derivatives. It is worth noting that the market sentiment variables are assumed to affect directly funding costs, but not CT1 systematically, though an increase in the VIX could increase the underlying volatility of bank assets, particularly if banks hold large equity portfolios, impacting their risk-weighted assets (RWAs). Over time, the indirect effects are captured in the simultaneous equation approach via funding costs. Finally, we add a crisis dummy (Crisis_d) that captures significant changes in the interaction between funding costs and bank solvency as well as other time-varying control variables. Market expectations

\footnotetext{
${ }^{18}$ The high correlation between VIX and LIBOR-OIS reported in the appendix is an artifact of the enormous spikes in both around the Lehman failure. Before and after the two did not move together. They indeed measure and capture different phenomena: the VIX captures a very broad change in volatility across all sectors of the economy (macroeconomic news in various parts of the world, changes in risk sentiment, geopolitical tensions); the LIBOR_OIS spread captures observed price behavior in levels in a sub-segment of the economy (unsecured interbank markets). It is very bank specific and time specific.
} 
regarding bank capitalisation changed abruptly with Lehman's bankruptcy. The dummy variable is defined as 0 from 2004Q4 to 2008Q3 and as 1 from 2008Q4 to 2013Q4. Despite the control variables, it is possible that the interaction between solvency and funding costs changed over time; e.g., we expect a stronger sensitivity of wholesale investors to solvency risk post-Lehman. We, therefore, also run our equations separately for two sub-samples (preand post-Lehman's default) to check for robustness.

To control for the macroeconomic environment, we use country-level credit growth (loan_growth) to capture loan demand in the local credit market. High private sector credit demand can be associated with periods of high capital ratios as banks frontload increases in CT1 to fund loan growth. One might argue that weak banks may be forced to boost their regulatory capital ratios to increase their resilience. To control for deliberate management actions, some of which were required by the supervisory agency to ease systemic risk, we construct a dummy variable to capture large swings in regulatory capital $\left(\Delta \mathrm{CT} 1 \_\mathrm{d}\right)$. Specifically, an increase of CT1 by more than 20 per cent quarter-on-quarter in nominal terms serves as a proxy for deliberate management action. ${ }^{19}$ This might stem from share issuance, asset sales, or public support measures. In fact, the various public interventions in 2008Q4 seem to be well captured by this dummy. We use five-year government CDS (CDS_gov) as a proxy of spillovers between sovereign risk and bank funding costs. Sovereign bonds constitute the safest assets in the countries in the sample and corporate bonds are priced against them. Higher sovereign CDS spreads are usually associated with higher corporate bond spreads. For the banks the interaction can be amplified via the value of implicit and explicit government guarantees. The value of the guarantees decreases with the credit worthiness of the guarantor.

The choice of instrumental variables for identification purposes in the simultaneous equation system (2) is of key importance. We have selected variables that fulfil the economic preconditions; i.e., they are directly related to one endogenous variable, but interact with the second one only indirectly via the first one. They fulfil the exclusion restriction. In line with the literature, drivers of CDS spreads include proxies of profitability and asset quality. We use loan loss provisions (LLP) as instrumental variable for the identification in the CT1 equation in Specification 1. LLP are a proxy for asset quality and directly affect CT1 as lower credit quality increases risk weighted assets and, thus, the denominator of the CT1 ratio. LLPs affect FVCDS only indirectly via counterparty risk, i.e. indirectly via CT1. Similarly, we use net income (NI) as an exogenous variable in the solvency equation. The main channel through which solvency affects NI is via funding costs which we capture in our model set-up. Other determinants of NI like commission income (fees and turn-over); staff costs, IT-costs, LLPs, participations, return on own portfolio are not directly affected by solvency. In addition, we include country-wide loan growth only in the CT1 equation. In Specification 2 we add a dummy variable that captures deliberate management action to change CT1 in the CT1 equation regulatory capital ( $\Delta \mathrm{CT1}$ 1_). It affects FVCDS only via

\footnotetext{
${ }^{19}$ This yields 70 observations for the dummy variable across all banks and quarters.
} 
CT1. We use the S\&P rating (S\&P (lag 1)), the sovereign CDS spread (CDS_gov), and the LIBOR-OIS spread for the identification of equation FVCDS in Specification 1. The lagged S\&P rating directly affects banks' CDS spreads; it can have an indirect impact on CT1 eventually via higher funding costs. Similarly, sovereign CDS spreads and the LIBOR-OIS spreads directly affect bank funding costs but not banks CT1 ratios.

Table 1 shows data coverage for the variables used in the estimation whereas Table 2 presents the summary statistics. Note that most of the variables are denoted in percentage points. This also holds for CDS spreads. The median value stood at $131 \mathrm{bps}$ across all banks over the entire period. The quartiles of the EDF measure are: 0.08 percent (first), 0.3 percent (second) and 0.94 percent (third). In addition, Table 3 provides a cross-correlation matrix of the dependent and independent variables used in the analysis. Interestingly, regulatory and market-based measures of bank solvency are not highly correlated with a correlation coefficient below 10 percent. EDF measures are more closely linked to other market-based measures including CDS spreads of government bonds and S\&P's bank ratings. While the components of the P\&L account are all linked in various ways, the correlation between NI and LLP at 40 percent is not particularly significant in our sample. This might be explained by the fact that there are many other determinants of NI so that the increasing LLPs do not mechanistically reduce NI. The latter is mostly determined by interest income (slope of the yield curve, bank specific funding costs) and commission income (fees and turn-over); staff costs, IT-costs, LLPs, participations, return on own portfolio and a number of other factors also play a role..$^{20}$

Potential stationarity-related concerns are addressed by performing the so-called meta unit root tests by Choi (2001) which includes unit-root tests for each variable separately and tests the p-values from these tests to produce an overall result. The null hypothesis of a unit root is rejected in most tests. The distribution of banks' solvency and funding costs is shown in Figure 1. CT1 ratios are presented in the top chart. Over the sample period, the first quartile is 7.89 percent, the third quartile is 11.55 percent, the mean is 10.5 percent and the median is 9.42 percent. The chart reveals banks' efforts to build their capital buffers in the wake of the financial crisis with average CT1 ratios increasing almost twofold from 7.4 percent in 2007 to 13.7 percent in 2013. The distribution has widened somewhat across time and outliers on the top of the distribution have become gradually more prominent. The bottom charts display the distribution of five-year EDF and five-year CDS market-based measures. The CDS first quartile is located at $45 \mathrm{bps}$, the second quartile is located at $131 \mathrm{bps}$ and the third quartile is located at 249 bps. The chart reveals that market-based measures for solvency and funding costs track each other quite closely, although in periods of stress, CDS spreads react more

\footnotetext{
${ }^{20}$ Even if variables LLP and NI were collinear, the estimated coefficients would still be consistent in our estimation procedure. The standard error would be inflated but that would not affect main finding, namely that solvency and funding costs are endogenously determined and that neglecting that interaction in stress tests leads to the systematic and significant underestimation of the effects on solvency of a given shock.
} 
strongly than EDF measures. Interestingly, funding costs remain elevated, even after the financial crisis subsided, despite banks' efforts to rebuild their regulatory capital ratios, suggesting that market-based hurdle rates may have increased in the wake of the crisis. This may be partly due to investors' risk reassessment of banks' underlying portfolios. The distribution of market-based measures has become wider relative to that for regulatory capital measures pointing at higher discrimination by investors across banks' creditworthiness.

Figure 2 displays the geographic evolution of the averages across banks of CT1, EDF, and CDS. Whereas North American banks' funding stress has subsided in the wake of stronger regulatory capital ratios built after the crisis, European banks have been hit by higher funding costs despite their strong capital ratios, particularly during the sovereign debt crisis in 2012, pointing at the adverse dynamics between banks and sovereigns.

\section{B. A Simultaneous Equation Approach}

To capture the contemporaneous realizations of bank solvency and bank funding costs, we estimate the solvency and funding equations using a simultaneous equation panel approach. For the purpose of stress testing, it is important to account for this endogeneity to avoid the underestimation of a solvency shock on financial stability.

We estimate the following model

$\mathrm{Y} \Gamma=\mathrm{XB}+\mathrm{U}$

In our analysis, $\mathrm{Y}$ is the vector of the two endogenous variables (i.e., solvency and funding costs), and $\mathrm{X}$ is a vector of exogenous variables including bank specific variables (to capture governance structures or business models), country specific variables (to control for timevarying macroeconomic conditions), and global variables (to capture global financial conditions and investors' risk appetite).

Rewriting (1) in reduced form simplifies the problem:

$\mathrm{Y}=\mathrm{XB} \Gamma^{-1}+\mathrm{U} \Gamma^{-1}=\mathrm{X} \Pi+\mathrm{V}$

Statistically, several conditions need to hold in order to extract the matrices B and $\Gamma$ from the estimated matrix $\Pi$, i.e., to solve the identification problem. If it is possible to deduce the structural parameters in equation (1) from the reduced form parameters in equation (2), then the model is identified. To identify the two endogenous variables, we need to find at least two exogenous sources of variation in bank solvency and funding costs. Then, we can apply two- and three-stage-least squares. The two-stage-least squares (2SLS) procedure has two steps. For each structural equation in (1), we regress each dependent variable on all 
exogenous variables in the system and obtain the predicted values for them. ${ }^{21}$ In the second step we regress the other dependent variable on the predicted value of the first dependent variable and on the remaining exogenous variables in the particular equation. The threestage-least squares (3SLS) combines the 2SLS with seemingly unrelated regressions (SUR) to account for the correlation structure of errors in each structural equation. We report either the 2SLS or 3SLS results, depending on the results of the statistical tests.

The statistical justification of our estimation approach can be tested by a series of standard tests in the context of 2SLS and 3SLS. First, we must test the relevance of the instruments to avoid the weak instrument problem (see Staiger and Stock (1997) for more details). For each specification, we report the F-statistic and the p-value, testing the joint relevance of the instruments for each equation. Second, we test for instrument exogeneity with two tests: we perform the J-test for each equation to check for exogeneity of the instruments. ${ }^{22} \mathrm{We}$ also apply the Lagrange multiplier test (LMF) suggested by Kiviet (1986). If the null hypothesis is not rejected for at least one equations in the system, these tests support the application of 2SLS as an IV instrumental variable estimator. Third, we test for endogeneity of the (right hand side) solvency and liquidity variables. Here we do not use the classical Hausman test that tests of all coefficients of two estimators (2SLS vs. OLS) are different but we apply the regression based Durwin-Wu- Hausman test that tests whether the coefficients of the (RHS) endogenous variable(s) are different. ${ }^{23}$ Finally we apply Hausman overidentification test to test the null hypothesis of 3SLS versus the alternative of 2SLS (provided 2SLS is validated by the exogeneity of instruments).

We compare those estimates with those obtained with a simple OLS estimator. The OLS model yields substantial biases and counterintuitive results, especially for the endogenous variables (see Table 12 and 13). Ultimately, our approach is a balancing act between addressing the potential weaknesses of the instruments and the biases of the OLS approach. The 2SLS and 3SLS results shown in the next section yield economically more intuitive results than the OLS results. They also appear robust across specifications including using two different measures of solvency. Nevertheless, the results should be interpreted with caution given the intrinsic difficulties in finding good exogenous instruments.

\section{Estimation RESULtS}

Table 4 summarises the results for the simultaneous panel estimation for the regulatory solvency measure CT1 and bank funding costs proxied by CDS spreads (in Section V we check the robustness of the results by replacing the regulatory ratio by the market-based

\footnotetext{
${ }^{21}$ It is important to note that 2 SLS in a simultaneous equation system has an important advantage over the classical single equation IV instrumental variable estimator: it does not use instruments that are outside of the system (i.e., not an exogenous variable in one of the equations).

${ }^{22}$ Bhargava (1991).

${ }^{23}$ Nakamura and Nakamura (1981) for more details.
} 
measure of solvency EDF). Table 4 shows results across various specifications for solvency and funding costs. For each specification, the first column shows the results of the bank solvency equation. The second column presents the results of the funding cost equation.

To explain the solvency equation, we use the following variables: loan loss provisions, net income, aggregate credit growth, and a crisis dummy. Loan loss provisions can be influenced by regulatory, tax, and profit smoothing considerations. Regardless of their motivation, higher provisions reduce profits and regulatory capital. ${ }^{24}$ Country-level loan growth is included as a macro control variable. If the market is growing, banks tend to increase capital to compete for market share and to protect their franchise value. A priori, the effect of loan growth on banks' CDS spreads is ambiguous. On the one hand, high loan growth could be associated with low CDS spreads, if it is interpreted as sign of strong market growth, solid macroeconomic fundamentals, and sound profitability. On the other hand, it can also be associated with high CDS spreads, when it is interpreted as sign of low credit standards, reckless lending, and mispricing of risk. We expect a positive effect of the crisis dummy on regulatory capital. With the Lehman collapse the market expectations regarding CT1 shifted from around 6 percent to 10 percent ("10 is the new 6"). Post-crisis CT1 ratios are, on average, about 323 bps higher now than they were before the crisis.

In the funding cost equation, we also include bank net income as a key determinant. We expect net income to be associated with lower funding costs as the banks' capacity to generate earnings and repay outstanding debt increases. Also, we include a set of marketbased variables, namely the bank's S\&P's rating, the sovereign CDS spread, the LIBOR-OIS spread, and the VIX. These variables are, however, excluded from the solvency equation as arguably, they do not impact directly CT1 nor RWA assets. They do so indirectly via funding costs. The bank's ratings directly affect the pricing of its credit derivative, but not its regulatory capital. ${ }^{25}$ Higher sovereign spreads often lead to higher bank spreads as the value of the implicit government guarantee is reduced. But they do not systematically affect banks regulatory capital. This is because bonds of the local sovereign have a zero-risk weight and are often held on hold-to-maturity portfolios. Tensions in interbank markets affect bank CDS spreads by rising wholesale funding costs. Finally, higher market volatility increases investors' risk premia pushing up funding costs.

Specification 1 is our baseline specification. It yields 782 observations from 38 banks. Bank funding costs are statistically and economically significantly associated with bank solvency. A 100 bps increase of the bank's CDS spread is associated with a reduction of a bank's CT1

\footnotetext{
${ }^{24}$ In contrast, the effect of provisions on funding costs depends on their motivation. Whereas higher provisioning rates designed to optimize taxation can increase inter-temporal profits and push down funding costs, provisions triggered by borrowers' lower credit quality is likely to be associated with higher funding costs.

${ }^{25}$ Ratings are eventually considering bank solvency, but ratings change infrequently and often lag CT1 changes such that we assume that they are not simultaneously determined with solvency in each quarter.
} 
ratio by 32 bps. ${ }^{26}$ This result is robust across specifications. Loan loss provisions are also significant; higher loan loss provisions are negatively correlated with regulatory capital. The crisis dummy is statistically significant, has the expected sign and an economically meaningful magnitude. The McElroy $\mathrm{R}^{2}$ is high at 90 percent. ${ }^{27}$

The CT1 ratio is statistically significant in the bank funding cost equation A 100 bps higher CT1 ratio is associated with a decrease of bank funding costs by $105 \mathrm{bps}$. This effect is robust to alternative specifications. In addition, net income has a statistically and economically significant impact on bank funding costs. Sovereign risk is also significant pointing at the existence of a sovereign-bank nexus, while the bank rating has the expected sign and is statistically significant. Tensions in the interbank market increase bank funding costs as expected. ${ }^{28}$ Global risk aversion is significant, though with a negative sign which we attribute to the correlation between LIBOR-OIS and VIX (Table 3). The crisis dummy is statistically significant, too. The McElroy $\mathrm{R}^{2}$ of 81 percent it suggests that the explanatory value of the system is high. As additional goodness-of-fit test we provide results for the adjusted $\mathrm{R}^{2}$ of 82 percent which suggests that the equation has high explanatory value to explain variations in bank funding costs.

In Specification 2, we study whether taking into consideration deliberate management actions to improve bank solvency has any impact on the results. Capital increases directly affect CT1, but systematically co-vary with bank CDS spreads only through changes in CT1. It turns out that the variable capturing sharp increases of capital is not statistically significant. The results for the endogenous variables and the other exogenous variables are basically unchanged; though the coefficient of CT1 in the funding cost equation is slightly higher at 113 bps. We enhanced Specification 2 by including banks' funding structure as one would expect that the risk premium component in funding costs increases with the funding tenor (Hull, White 2000). Ceteris paribus, the CT1 ratios of banks with larger shares of short-term funding are likely to be less affected by an increase in 5 year CDS spreads than those of banks with larger shares of long-term funding. We test for this effect by including the share

\footnotetext{
${ }^{26}$ The 32 basis points are an average across all banks in the sample; the impact of an increase in funding costs on an individual bank depends on the share of funding that is CDS sensitive (mostly unsecured wholesale funding), the ratio of risk weighted assets to total assets, the term structure of funding, and the pass-through of higher funding costs to new assets. The banks in the sample are large internationally active banks with significant reliance on credit-sensitive funding instruments during the sample period. At the same time, competition in credit markets is high, constraining banks' ability to pass-through rising funding costs to customers. On balance, we regard the magnitude of the coefficient as plausible taking as a benchmark the largest bank of the sample. At end-2013, ING N.V. had RWAs of 299bn, fixed rate debt securities in issue maturing within 1 year of $37 \mathrm{bn}$, floating rate debt securities of $30 \mathrm{bn}$, interest-bearing amounts due to banks of $25 \mathrm{bn}$, corporate deposits of $60 \mathrm{bn}$, and financial liabilities at fair value of $97 \mathrm{bn}$. Assuming that half liabilities reprice within the quarter, one quarter of financial liabilities at fair value reprice within the quarter, and no passthrough effects, the impact of a 100 bps shock to wholesale funding amounts to $33 \mathrm{bps}$ of RWAs.

${ }^{27}$ The McElroy R ${ }^{2}$ provides a goodness-of-fit measure for systems of equations (McElroy (1977)).

${ }^{28}$ The variables that serve as instruments in the funding cost equations are significant. We conclude that, given our assumptions, the results do not reject their usefulness as instruments.
} 
of short-term debt in total assets and the interaction term between this variable and the variable FVCDS as explanatory variable in both equations. We find that the main results for the endogenous variables are robust with respect to the signs and the significance levels. At the same time, the coefficient of FVCDS in the solvency equation increases to -1.1 from -0.32 . This effect is partly counterbalanced by the positive sign of the interaction term $(0.06)$. An increase of the FVCDS of, say, 105 bps decreases the CT1 ratio by 100 bps if the bank has no short-term debt at all. If short-term amounts to 10 per cent of total assets (the average in the sample), the effect is reduced by 60 basis points to about $50 \mathrm{bps}$. This has roughly the same magnitude that the corresponding parameter in Specification 2 in Table 4. Regarding the other parameters in the specification, the crisis dummy remains unchanged, the LLP becomes insignificant, but NI becomes significant. Regarding the funding equation, the parameter of the CT1 ratio increases to -0.87 from -1.13 . The coefficient of the other variables (NI, S\&P, CDS_gov) remain unchanged. The variable VIX is now insignificant, the coefficient of the LIBOR_OIS spread decreases from 1.71 to 1.03 and that of the crisis dummy from 2.97 to 1.97 .

To allow for non-linear effects, we add the squared values of the endogenous variables in Specification 3. ${ }^{29}$ These variables are calculated as squared quarter-on-quarter first differences while maintaining the direction of the change (i.e., the transformation is sign preserving). We treat these variables as additional endogenous variables and include their fitted values of the underlying equations. CT1 remains significant in the funding cost equation while CDS spreads remain significant in the solvency equation. We do not find supporting evidence of the existence of non-linear effects between funding costs and regulatory capital, probably related to the lack of sensitivity of capital requirements to rising funding costs. The additional variables leave most other coefficients basically unaffected, except for the coefficient of loan loss provisions that becomes significantly higher. To check the stability of parameters across time, we rerun Specification 3 for two sub-samples (preand post-Lehman). However, data restrictions (there are only 96 observations in the pre-crisis sample) hinder statistical analysis and the system fails to yield meaningful results.

The tests statistics for the econometric specifications are generally satisfactory (Table 5). The quality of instruments test rejects the null of weak instruments in all equations if we include the contemporary S\&P's bank rating in the funding cost equation. We therefore instrument credit ratings by their lagged value. The J-Test and the LMF test fail to reject the null of exogenous instruments. The Durbin-Hausman-Wu test is consistent with the endogeneity of the (RHS) dependent variables. The system overidentification test for the 3SLS method suggests a preference for 2SLS over 3SLS (and iterated 3SLS) for Specifications 1, 2 and 3.

To gauge the direction of the likely bias of OLS due to the endogeneity of bank solvency and funding costs, we run the three specifications using OLS (Table 12). For Specification 1 we

\footnotetext{
${ }^{29}$ However, we treat this approach as first approximation as accounting for non-linearities in linear models is no equivalent to constructing nonlinear models of the underlying processes.
} 
obtain statistically significant coefficients of 0.17 and 0.14 for the coefficients of CT1 and CDS spreads, respectively. Similar results are obtained for Specifications 2 and 3.

Counterintuitively, the results suggest that higher funding costs are associated with higher $\mathrm{CT} 1$ ratios and that higher $\mathrm{CT} 1$ ratios are associated with higher funding costs. This reveals that without controlling for spurious correlations and unobservable shocks, OLS estimates significantly underestimate the negative relationship between funding costs and solvency. For Specification 1, the OLS coefficient of CDS in the solvency equation suggests a positive relationship between funding costs and bank capital with an estimated coefficient of 0.14 rather than the negative impact of -0.32 estimated under the simultaneous panel approach.

\section{Robustness Checks}

This section offers additional support for our findings that solvency and funding costs are determined simultaneously. We perform several robustness checks using a market-based proxy for bank solvency, and introducing a measure of liquidity risk.

\section{A. Introducing a Market-based Measure of Bank Solvency}

To check the robustness of our results to the solvency measure, we re-run the specifications shown in the previous section using the market-based EDF measure as a proxy of bank solvency. Table 6 shows the results.

In Specification 1, the analysis is based on 946 observations for 38 banks in six countries from 2004Q4 to 2013Q4. While the test for weak instruments suggests that the instruments used in Table 4 are weak, one would expect that the LIBOR-OIS spread and the VIX are more likely to co-vary with the market solvency measure than with regulatory capital. We therefore include these two variables in the solvency equations shown in Table 6. The results show that the impact of bank funding costs on the market measure of solvency is statistically and economically significant. A 100 bps increase of CDS spreads is associated with average increase in the EDF of 66 bps. The bank specific variable provisioning ratio and the country specific variable loan growth are not statistically and economically significant. As suggested by the test for weak instruments the market indicators LIBOR-OIS and VIX are significant in the solvency equations, too. The VIX now has the expected sign, but the LIBOR-OIS spread influences solvency negatively through funding cost reflecting high correlation across markets. The crises dummy is statistically significant, but has a negative sign. This is consistent with the results in Table 4, as CT1 and EDF have different signs. After controlling for higher funding costs, money market conditions, and general risk aversion, EDF is somewhat lower post-Lehman pointing at the high capitalization efforts by banks covered in the sample (as demonstrated by the positive sign of the crisis dummy in the CT1 equations in Table 4). The $\mathrm{R}^{2}$ is high at 78 percent.

The association between the market measure of solvency and funding costs is positive and highly significant at the one per cent level; the coefficient 1.40 is economically significant. A money market shock - as measured by a spike in the LIBOR-OIS spread - translates into an 
increase in bank funding costs. Global risk aversion (VIX) reduces bank funding costs. While the coefficient is statistically significant, it has the wrong sign. We attribute this to the large spikes in LIBOR-OIS when VIX also spiked during the heights of the crisis. Changes in sovereign CDS do not directly affect bank funding costs. Finally, the crisis dummy is significant; after Lehman funding costs are generally higher. The $\mathrm{R}^{2}$ is high at 77 per cent. The McElroy $\mathrm{R}$ is very high at just under 100 percent which suggests that the specifications including market based measures of solvency and liquidity are less relevant than the specifications including the regulatory solvency measure CT1.

In Specification 2, we study whether taking into consideration deliberate management action that aims at improving bank solvency has an impact on the results. It turns out that this variable is not statistically significant. The coefficients and standard errors of the other exogenous variables LIBOR_OIS and VIX remain largely unaffected. However, the crises dummy is not statistically significant anymore. In addition, the coefficients and standard errors of the endogenous variables are basically unchanged.

Again, we add the squared changes of the endogenous variables in the current quarter to test for non-linearities in Specification 3. By contrast to the results shown in Table 4, funding costs have a significant non-linear impact on the solvency equation. As funding costs increase, banks' distance to default decreases pushing up solvency risk. The coefficients of the other endogenous variables remain statistically and economically significant, with very similar coefficients. The same holds true for the coefficients of the exogenous variables.

The tests statistics are generally satisfactory (Table 7). The quality of instruments test rejects the null of weak instruments in all equations. The J-Test and the LMF test fail to reject the null of exogenous instruments (except for the FVCDS equation in Specification 3 which is not important since the null is kept for the EDF equation in the same specification). The Durbin-Hausman-Wu test for the solvency equation is only significant at the 7 percent level in Specification 1 and not significant in Specification 2, however insignificant for the other specifications. It suggests that endogeneity is less of an issue for the market based solvency measure. The system overidentification test is satisfactory for 3SLS across all specifications.

We also assess the direction of the bias generated by running an OLS regression on the market-based solvency measure. Results are reported in Table 13. In line with the results obtained for the regulatory capital measure, OLS coefficients underestimate the impact of solvency risk on funding costs across all specifications, albeit to a smaller extent. For Specification 1, the OLS coefficient of CDS in the solvency equation at 0.59 lies below the 0.66 estimate under the simultaneous panel approach.

\section{B. Introducing a Measure of Liquidity Risk}

Funding costs are likely to be determined by banks' exposure to liquidity risk as recently shown by Acharya and Mora (2015). Changes in the maturity or composition of banks' funding can have important implications for measures of default risk. To address this 
concern, we introduce a measure of liquidity risk (LiRisk) to control for banks' liquidity risk bearing capacity. For the baseline specification using the regulatory capital measure, the results are shown in Table 8 . The impact of regulatory capital on funding costs is robust to the introduction of the liquidity measure. The coefficient decreases just slightly from 1.048 to 1.028 but remains statistically significant at the 1 percent confidence level. Table 10 reports the results for the market-based solvency measure. The liquidity indicator is not statistically significant across specifications. Again, the coefficient of baseline regressors is stable, with the impact of EDF slightly decreasing from 1.40 to 1.37 and remaining statistically significant at the 1 percent confidence level.

A caveat of the analysis is that a bank's exposure to other risks may affect its liquidity. Any exposure may expose a bank to multiple risks and can erode a bank's liquidity position or affect its funding costs, thereby increasing its liquidity risk.

\section{Application to Stress Testing}

This section illustrates the relevance of the empirical analysis for stress testing. We apply the estimated relationship between solvency and funding costs to project banks' capital ratios under stress. The objective of stress testing is to assess banks' resilience to adverse macroeconomic developments. While banks are routinely required to incorporate funding cost projections in their stress testing submissions, these are typically driven by risk factors linked to the scenario, notably the macroeconomic environment and the evolution of benchmark rates, but less so to idiosyncratic risk linked to banks' capital position under stress. The aim of this section is to provide an estimate of the additional impact of endogenizing the solvency-funding cost channel on banks' capital ratios in a stressful environment. We base our analysis on the adverse macroeconomic scenario developed by the ECB for the 2014 EU-wide stress test conducted by the European Banking Authority (EBA).

To illustrate the magnitude of the interaction between solvency and funding costs on banks' capital ratios we use data on European banks disseminated by EBA on the 2014 EU-wide stress test exercise. ${ }^{30}$ The EU-wide stress test was conducted on a sample of 124 EU banks under the assumption of a static balance sheet which implies no new growth and constant business mix and model throughout the time horizon of the exercise. The resilience of EU banks was assessed over a period of three years-i.e., 2014-2016.

Of the 15 EU banks covered in our sample, 11 banks were also included in the EU stress test exercise. We focus the analysis on this subset of banks. At the cut-off date, the aggregate common equity tier I (CET1) ratio for our sample stood at 14.5, which is significantly higher than the aggregate CET1 ratio for the entire sample at 11.1 percent. At the same time, the impact of stress on bank's capital ratios is of similar magnitude across samples: 283 bps for our subset of banks relative to $270 \mathrm{bps}$ for the entire population of banks covered in the

\footnotetext{
${ }^{30}$ See European Banking Authority (2014b).
} 
exercise. This section addresses the question of whether integrating second-round effects via the solvency and funding cost nexus would have had a significant impact on this capital shortfall.

We use the coefficients shown in Specification 1 (Table 4) to endogenize banks' funding costs. While econometric results are cast in terms of CT1 rather than CET1 as the measure of regulatory capital, we expect the undisclosed value of CT1 for the banks in the sub-sample to be close to their CET1 as the weighted-sized gap between Tier 1 (a broader measure than CT1) and CET1 stood at only $100 \mathrm{bps}$ in $2013 .{ }^{31} \mathrm{We}$ assume that the average funding structure of the 11 banks included in the EU stress test exercise is similar to that of the average bank in our 15-bank sample. ${ }^{32}$ While this is a reasonable assumption given the composition of the two samples, individual results might be overestimated for banks that focus on retail funding and underestimated for banks with greater reliance on wholesale funding. Our estimated relationship suggests that:

$$
\begin{aligned}
& \Delta F V C D S_{1, t}=\alpha \cdot \Delta C T 1_{i, t}^{*}+\beta \cdot \Delta N I_{i, t} \\
& \Delta C T 1_{i, t}^{f c}=\delta \cdot \Delta F V C D S_{1, t}
\end{aligned}
$$

Where $\Delta C T_{i, t}^{*}$ denotes bank i's change in regulatory capital at time t excluding the interaction effect and $\Delta C T_{i, t}^{f c}$ denotes the interaction effect. The marginal effect of capital (net income) in the funding equation is denoted by $\alpha(\beta)$, and the marginal effect of funding cost in the capital equation is denoted by $\delta$. Note that allowing for the interaction effect at time $t$ carries forward to $t+1$ due to its impact on $\triangle C T 1_{i, t+1}^{*}$ and therefore on $\triangle F V C D S_{, t+1}$.

Denote by $\{t, t+j\}$ the stress testing horizon. We can iterate equation (3) forward to calculate the impact of the interaction effect on bank i's capital ratio at time $t+j$ :

$$
\begin{aligned}
& \Delta C T 1_{i, t+j}^{f c}=\left\{\alpha^{j+1} \cdot \delta^{j+1} \cdot \Delta C T 1_{i, t}^{*}+\alpha^{j} \cdot \delta^{j+1} \cdot \beta \cdot \Delta N I_{i, t}\right\}+\left\{\alpha^{j} \cdot \delta^{j} \cdot \Delta C T 1_{i, t+1}^{*}+\alpha^{j-1} \cdot \beta \cdot \delta^{j} \cdot \Delta N I_{i, t+1}\right\} \\
& +\ldots+\left\{\alpha \cdot \delta \cdot \Delta C T 1_{i, t+j}^{*}+\delta \cdot \beta \cdot \Delta N I_{i, t+j}\right\}
\end{aligned}
$$

Interestingly, equation (4) reveals a hysteresis effect of solvency shocks in banks' capital ratios. An initial disturbance to bank capital is long-lived due to its impact through the funding cost channel. The rate of decay is determined by the interaction between the elasticity of capital to funding costs $(\delta)$ and the elasticity of funding costs to capital $(\alpha)$.

\footnotetext{
${ }^{31}$ We proxy bank CT1 ratios by CET1 ratios as EBA's CET1 projections are reported under the transitional arrangements of Basel III which are close to CT1 ratios.

${ }^{32}$ EBA (2014b) does not disclose the liabilities composition of the banks included in the EU-wide stress test.
} 
Next, we quantify banks' susceptibility to adverse solvency-funding cost dynamics for the selected 11 EU banks. To conduct the analysis, we use the individual bank projections of CET1 and net income ratio (NI), as projected by EBA in 2014, as a starting point of the iterative process. We then use the estimated coefficients for net income (NI) and regulatory capital (CT1) in the funding cost equation (FVCDS) to parameterize the adverse dynamics between bank solvency and funding costs and their ultimate impact on bank' capital ratios at the end of the stress test horizon.

In 2014, the weighted-average CET1 ratio for our sample of banks decreases by $130 \mathrm{bps}$ under the adverse scenario, from a weighted average of 14.5 percent in 2013 to 13.2 percent in 2014. At the same time, the average net income ratio (NI) falls by 40 bps to -0.2 percent from 0.2 percent in 2013. Given the estimated elasticities of funding costs to CT1 and NI, the solvency shock triggers an increase in banks' marginal wholesale funding cost of $160 \mathrm{bps}$ in 2014. This shock generates a further reduction of banks' capital ratios by 51 bps. The additional drop in capital buffers feeds into the stress test exercise as an idiosyncratic funding shock the following year. This iterative process continues throughout the stress test horizon. Table 14 reports the results at the bank level for the entire stress test horizon over 2014-2016.

The overall effect is significant. While macroeconomic stress reduces the aggregate capital ratio by 283 bps over 2014-2016, the overall impact, including the macro shock and the adverse dynamics of the solvency-funding cost nexus slashes banks' average capital ratio by $414 \mathrm{bps}$. This suggests that the impact of second-round effects of the solvency-funding cost nexus might erode banks' capital ratios by about half of the capital shortfall estimated by EBA. Figure 3 shows the contributing factors to the shortfall in the aggregate CET1 by year. For the average bank in the sample, the interaction effect on CET1 is 51 bps in 2014, 43 bps in 2015, and 37 bps in 2016. ${ }^{33}$ Due to the adverse reinforcing dynamics, the relative impact of the interaction effect vis-a-vis the macro effect increases throughout the stress test horizon, from 40 percent in 2014 to over 50 percent in 2016.

The impact on capital loss in monetary units is even larger as weaker banks tend to post higher RWAs. Overall, the interaction effect triggers a reduction in aggregate capital by $€ 3.8$ billion in $2014, € 3.3$ billion in 2014 , and $€ 2.8$ billion in 2014 for our sample of banks. This represents around half of the aggregate capital losses estimated by EBA for this subset of banks from adverse economic developments over the three-year horizon.

The effect of the interaction between solvency and funding costs is significant in part because the impact of funding cost rises non-linearly over the stress test horizon. This is because net

\footnotetext{
${ }^{33}$ This estimate reflects the impact of an idiosyncratic funding shock whereby a bank's cost of funds depends on its own capital position. By taking bank solvency into account, this element captures a key amplification channel evident during the global financial crisis. On the other hand, aggregate shocks to funding costs remain the same as under the EBA stress test scenario.
} 
income and capital deteriorate further owing to adverse reinforcing dynamics. The EBA's stressed capital ratios do include non-bank specific funding cost effects from adverse macroeconomic developments, risk aversion and liquidity strains, but not the bank-specific feedback effect modelled in this paper. ${ }^{34}$ The application to stress tests shows that banks with shorter funding tenors, and/or greater reliance on CDS sensitive funding instruments (i.e., unsecured wholesale funding) and/or lower RWA to total assets ratios are more affected by the feedback effect of solvency on funding costs. We conclude that a bank's funding structure is not only relevant for its funding liquidity risk exposure, but also for its exposure to solvency shocks. On the other hand, the cumulated impact could be more severe in a tail event as bank funding structures might be further impaired under stress. In a crisis, wholesale funding tends to shift to shorter-dated tenors, increasing the amount of liabilities which need to be rolled over at higher funding rates.

\section{SUMmary AND CONCLUSIONS}

While the existence of a relationship between bank solvency and funding costs is widely accepted in the literature, its estimated magnitude has been typically small. Our results suggest a larger impact of solvency on funding costs than suggested by earlier studies. The stability of the coefficients is confirmed when we consider alternative measures of solvency risk and for banks' capacity to bear liquidity risk. These new results could be in part due to our newly constructed dataset, which exploits high quality supervisory data. They could also be driven by the econometric strategy to implement a 3SLS simultaneous equation approach, by contrast to the OLS-based estimates which are prevalent in the existing literature. Indeed, our results show that OLS underestimates the solvency-liquidity interaction nexus. This might be due to investors' expectations that a weaker bank might raise capital to rebuild its capital buffer in order to ease funding pressures or meet regulatory expectations. While a simultaneous equation approach has its own challenges related to the difficulty of finding suitable instruments and avoiding overidentification, our statistical tests and robustness checks provide some comfort on the estimated coefficients in the interaction between solvency and funding costs. Still, the results should be interpreted with caution bearing the limitations of the approach in mind.

Our results suggest that the interaction between solvency and funding shocks in supervisory stress tests models is quantitatively relevant. Our analysis suggests that, by incorporating the dynamic interaction between solvency and funding costs in the 2014 EU-wide stress test, stressed capital ratios could be depleted by a further half of the capital shortfall estimated in the original EBA analysis. This is a conservative estimate as EBA methodological approach

\footnotetext{
${ }^{34}$ See European Banking Authority (2014a).
} 
partially incorporates rising funding costs linked to the scenario. ${ }^{35}$ The results are also highly relevant for cost impact assessments of capital regulation, as the costs of higher capital requirements are partly offset by lower debt servicing costs. Our results provide a foundation for calibrating that effect in quantitative cost-benefit analyses of bank regulation. The analysis also points at the merits of incorporating solvency and liquidity interactions in the design of prudential regulation. While our results are encouraging, future research should assess their robustness using larger high-quality samples, and, if feasible, a broader set of instruments to address remaining endogeneity concerns.

\footnotetext{
${ }^{35}$ To the extent that stressed credit spreads under the adverse scenario reflect a weakened capital position of the banking system, the rise in wholesale funding costs projected under EBA incorporates a 'systemic' funding shock whereby banks' cost of funds depend on the position of the system as a whole.
} 
Table 1. Data Coverage

\begin{tabular}{|c|c|c|}
\hline Variable & $\begin{array}{l}\text { Available observations } \\
\text { (number) }\end{array}$ & $\begin{array}{c}\text { Available } \\
\text { observations (in } \\
\text { percent) }\end{array}$ \\
\hline \multicolumn{3}{|l|}{ Dependent variable } \\
\hline $\mathrm{CT} 1$ & 1632 & 81.7 \\
\hline EDF & 1625 & 81.3 \\
\hline FVCDS & 1625 & 81.3 \\
\hline CET1 & 1159 & 58.0 \\
\hline Tier 1 & 477 & 23.9 \\
\hline FVOAS & 764 & 38.2 \\
\hline ptb & 1184 & 59.3 \\
\hline tce & 1458 & 73.0 \\
\hline \multicolumn{3}{|l|}{ Bank characteristics } \\
\hline assets_usd & 1847 & 92.4 \\
\hline NPL & 1365 & 68.3 \\
\hline LLR & 1569 & 78.5 \\
\hline LLP & 1839 & 92.0 \\
\hline LTD & 1719 & 86.0 \\
\hline st_debt & 1565 & 78.3 \\
\hline excess_reserves & 1823 & 91.2 \\
\hline fx liabilities & 276 & 13.8 \\
\hline NIE & 1839 & 92.0 \\
\hline NII & 1815 & 90.8 \\
\hline NI & 1839 & 92.0 \\
\hline Fitch & 1311 & 65.6 \\
\hline Moodys & 1395 & 69.8 \\
\hline$S \& P$ & 1514 & 75.8 \\
\hline \multicolumn{3}{|l|}{ Country variables } \\
\hline ER_regime & 1998 & 100.0 \\
\hline CDS_gov & 1515 & 75.8 \\
\hline loan_growth & 1997 & 100.0 \\
\hline \multicolumn{3}{|c|}{$\begin{array}{l}\text { Note: Coverage of key variables for the sample of European } \\
\text { and North American banks from 2004Q4 to 2013Q4. } \\
\text { Sources: National supervisory data; Bloomberg L.L.P., Thomson }\end{array}$} \\
\hline \multicolumn{3}{|c|}{$\begin{array}{l}\text { Reuters; Moody's KMV; and IMF, International Financial Statistics } \\
\text { database. }\end{array}$} \\
\hline
\end{tabular}

CInternational Monetary Fund. Not for Redistribution 


\section{Table 2. Summary Statistics of the Dependent and Independent Variables}

\begin{tabular}{|c|c|c|c|c|c|c|c|c|}
\hline Variable & Min & 1st Quantile & Median & Mean & 3rd Quantile & Max & NAs & $\begin{array}{l}\text { Standard } \\
\text { Deviation }\end{array}$ \\
\hline СТ1 & -13.7 & 7.9 & 9.4 & 10.5 & 11.6 & 111.2 & 366 & 9.8 \\
\hline EDF & 0.0 & 0.1 & 0.3 & 0.9 & 0.9 & 21.4 & 373 & 1.6 \\
\hline FVCDS & 0.0 & 0.4 & 1.3 & 2.0 & 2.5 & 17.4 & 381 & 2.2 \\
\hline$\Delta C T 1^{2}$ _sign & -525.3 & 0.0 & 0.0 & -0.1 & 0.1 & 757.8 & 423 & 28.2 \\
\hline$\Delta \mathrm{EDF}^{2}$ _sign & -87.4 & 0.0 & 0.0 & 0.1 & 0.0 & 158.3 & 456 & 6.8 \\
\hline$\triangle \mathrm{FVCDS}^{2}$ _sign & -73.3 & 0.0 & 0.0 & 0.1 & 0.1 & 132.0 & 427 & 5.9 \\
\hline CET1 & -13.7 & 6.4 & 7.9 & 7.8 & 10.0 & 19.7 & 839 & 4.0 \\
\hline Tier 1 & 4.4 & 8.6 & 10.4 & 14.7 & 12.1 & 114.6 & 1299 & 18.1 \\
\hline ptb & 10.2 & 91.4 & 145.4 & 163.7 & 217.9 & 577.9 & 814 & 93.1 \\
\hline tce & 0.0 & 343.2 & 483.5 & 485.9 & 647.8 & 1726.0 & 540 & 249.4 \\
\hline assets_usd & 28 & 78 & 162 & 359 & 401 & 2460 & 151 & 480.1 \\
\hline LLP & -0.2 & 0.0 & 0.1 & 0.1 & 0.2 & 2.0 & 183 & 0.2 \\
\hline NI & -4.7 & 0.1 & 0.2 & 0.1 & 0.3 & 2.1 & 160 & 0.3 \\
\hline Fitch & 2.0 & 4.0 & 4.0 & 4.9 & 6.0 & 10.0 & 687 & 1.7 \\
\hline Moodys & 1.0 & 4.0 & 5.0 & 5.3 & 7.0 & 15.0 & 603 & 2.3 \\
\hline$S \& P$ & 2.0 & 5.0 & 5.0 & 5.7 & 7.0 & 11.0 & 484 & 1.8 \\
\hline$\Delta \mathrm{CT} 1 \_\mathrm{d}$ & 0.0 & 0.0 & 0.0 & 0.0 & 0.0 & 1.0 & 423 & 0.2 \\
\hline CDS_gov & 0.0 & 0.2 & 0.4 & 0.4 & 0.5 & 1.9 & 483 & 0.3 \\
\hline loan_growth & -7.7 & -0.1 & 1.3 & 1.0 & 2.2 & 8.2 & 1 & 1.9 \\
\hline VIX & 11.0 & 13.6 & 18.3 & 20.5 & 24.3 & 58.3 & 0 & 9.5 \\
\hline LIBOR_OIS & 0.1 & 0.1 & 0.2 & 0.3 & 0.4 & 2.1 & 0 & 0.4 \\
\hline Crisis_d & 0 & 0 & 1 & 0.6 & 1 & 1 & 0 & 0.5 \\
\hline
\end{tabular}

Notes: Summary descriptive statistics of the sample of European and North American banks from 2004Q4 to 2013Q4. Source: national supervisory data, Bloomberg, Datastream, Moody's KMV, International Financial Statistics. All variables are expressed in percent, except assets in USD billion, agency ratings in a numerical scale (from 1 for AAA to 24 for D), and two dummy variables, i.e. $\triangle \mathrm{CT} 1$ _d and Crisis_d (values: 0,1 ). Key variables include: CT1 (core Tier 1 to RWAs); EDF (Moody's 5y expected default frequency); FVCDS (Moody's 5y fair value credit spread); $\triangle C T 1^{2}$ _sign (square quarter-on-quarter growth rate of CT1, sign

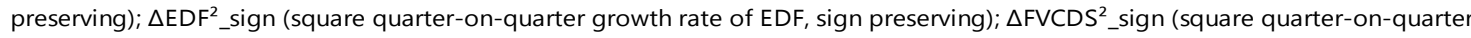
growth rate of FVCDS, sign preserving); CET1 (common equity Tier 1 to RWAs); Tier 1 (Tier 1 equity to RWAs); ptb (price to tangible book equity); tce (tangible common equity to total assets); assets_usd (total assets in billion USD); LLP (loan loss provisions to total assets); NI (net income to total assets); Fitch, Moodys, S\&P (agency bank's rating with government uplift mapped to a numerical scale from 1 (AAA) to 24 (D)); $\triangle C T 1$ d (dummy variable with 1 if quarter_on_quarter growth of CT1 is $>20 \%$; 0 otherwise); CDS_gov (5y government CDS); loan_growth (quarter_on_quarter growth of loans to the private sector); VIX (implied volatility of S\&P 500 index options); LIBOR-OIS ( $3 \mathrm{~m}$ libor usd to overnight index swap); and Crisis_d (dummy variable with 1 for 2008Q4 to 2013Q4; 0 otherwise). 


\begin{tabular}{|c|c|c|c|c|c|c|c|c|c|c|c|c|c|c|c|c|}
\hline \multicolumn{17}{|c|}{ Table 3. Cross-Correlation Matrix of the Dependent and Independent Variables } \\
\hline & $\Delta C T 1 \_d$ & CDS_gov & CT1 & Crisis_d & EDF & FVCDS & LIBOR_OIS & LiRisk & loan_growth & LLP & NI & OIS & $S \& P$ & $\Delta \mathrm{CT} 1^{2}$ _sign & $\triangle \mathrm{FVCDS}^{2}$ _sign & VIX \\
\hline$\Delta \mathrm{CT1}$ _d & 1.00 & 0.00 & -0.05 & 0.00 & 0.05 & 0.07 & 0.22 & 0.08 & -0.03 & 0.11 & -0.10 & 0.02 & -0.03 & 0.04 & 0.03 & 0.18 \\
\hline CDS_gov & 0.00 & 1.00 & 0.10 & 0.53 & 0.41 & 0.39 & 0.02 & -0.09 & -0.31 & 0.05 & -0.01 & -0.50 & 0.12 & 0.04 & 0.03 & 0.21 \\
\hline $\mathrm{CT} 1$ & -0.05 & 0.10 & 1.00 & 0.20 & 0.09 & 0.12 & -0.03 & -0.02 & -0.06 & -0.04 & -0.02 & -0.19 & -0.06 & 0.13 & -0.04 & 0.00 \\
\hline Crisis_d & 0.00 & 0.53 & 0.20 & 1.00 & 0.40 & 0.48 & 0.11 & -0.10 & -0.52 & 0.19 & -0.17 & -0.91 & 0.26 & 0.04 & -0.05 & 0.40 \\
\hline EDF & 0.05 & 0.41 & 0.09 & 0.40 & 1.00 & 0.86 & 0.12 & -0.05 & -0.37 & 0.30 & -0.21 & -0.38 & 0.28 & 0.03 & 0.19 & 0.26 \\
\hline FVCDS & 0.07 & 0.39 & 0.12 & 0.48 & 0.86 & 1.00 & 0.33 & -0.06 & -0.45 & 0.35 & -0.32 & -0.49 & 0.28 & 0.04 & 0.24 & 0.40 \\
\hline LIBOR_OIS & 0.22 & 0.02 & -0.03 & 0.11 & 0.12 & 0.33 & 1.00 & -0.03 & -0.24 & 0.29 & -0.29 & -0.17 & -0.09 & -0.02 & 0.11 & 0.85 \\
\hline LiRisk & 0.08 & -0.09 & -0.02 & -0.10 & -0.05 & -0.06 & -0.03 & 1.00 & 0.06 & -0.05 & -0.03 & 0.08 & -0.12 & -0.01 & 0.00 & -0.05 \\
\hline loan_growth & -0.03 & -0.31 & -0.06 & -0.52 & -0.37 & -0.45 & -0.24 & 0.06 & 1.00 & -0.31 & 0.21 & 0.49 & -0.11 & 0.01 & -0.08 & -0.43 \\
\hline LLP & 0.11 & 0.05 & -0.04 & 0.19 & 0.30 & 0.35 & 0.29 & -0.05 & -0.31 & 1.00 & -0.42 & -0.20 & 0.26 & 0.01 & 0.02 & 0.36 \\
\hline $\mathrm{NI}$ & -0.10 & -0.01 & -0.02 & -0.17 & -0.21 & -0.32 & -0.29 & -0.03 & 0.21 & -0.42 & 1.00 & 0.19 & -0.04 & -0.01 & -0.24 & -0.32 \\
\hline OIS & 0.02 & -0.50 & -0.19 & -0.91 & -0.38 & -0.49 & -0.17 & 0.08 & 0.49 & -0.20 & 0.19 & 1.00 & -0.24 & -0.03 & 0.02 & -0.40 \\
\hline S\&P & -0.03 & 0.12 & -0.06 & 0.26 & 0.28 & 0.28 & -0.09 & -0.12 & -0.11 & 0.26 & -0.04 & -0.24 & 1.00 & -0.01 & 0.00 & -0.03 \\
\hline$\Delta \mathrm{CT1} 1^{2}$ _sign & 0.04 & 0.04 & 0.13 & 0.04 & 0.03 & 0.04 & -0.02 & -0.01 & 0.01 & 0.01 & -0.01 & -0.03 & -0.01 & 1.00 & 0.02 & -0.01 \\
\hline$\triangle \mathrm{FVCDS}^{2}{ }^{2}$ sign & 0.03 & 0.03 & -0.04 & -0.05 & 0.19 & 0.24 & 0.11 & 0.00 & -0.08 & 0.02 & -0.24 & 0.02 & 0.00 & 0.02 & 1.00 & 0.08 \\
\hline VIX & 0.18 & 0.21 & 0.00 & 0.40 & 0.26 & 0.40 & 0.85 & -0.05 & -0.43 & 0.36 & -0.32 & -0.40 & -0.03 & -0.01 & 0.08 & 1.00 \\
\hline $\begin{array}{l}\text { Notes: Correl } \\
\text { Financial Statis } \\
\text { variables includ } \\
\text { to 2013Q4; } 0 \text { o } \\
\text { reserves, and sc } \\
\text { sector); LLP (loa } \\
\text { (square quarter }\end{array}$ & $\begin{array}{l}\text { a); EDF (M } \\
\text { debt witl } \\
\text { orovisions } \\
\text { arter grow }\end{array}$ & $\begin{array}{l}\text { ariable with } \\
\text { y's 5y expec } \\
\text { otal assets); } \\
\text { ate of }(\mathrm{CT} 1 \text {, s }\end{array}$ & $\begin{array}{l}\text { f quarte } \\
\text { d defaul } \\
\text { and } 20 \\
\text { I net in } \\
\text { n preser }\end{array}$ & $\begin{array}{l}\text {-on_quarte } \\
\text { frequency } \\
\text { to short-t } \\
\text { ome to tot } \\
\text { ing); } \Delta \mathrm{FVC}\end{array}$ & $\begin{array}{l}\text { rowth c } \\
\text { VCDS ( } \\
\text { nhole } \\
\text { ssets); }\end{array}$ & $\begin{array}{l}\text { ody's } 5 y \\
\text { e liabilitic } \\
\text { (overnig }\end{array}$ & 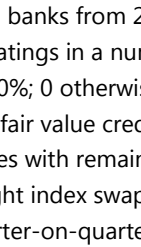 & $\begin{array}{l}2004 \mathrm{Q} 4 \mathrm{t} \\
\text { merical sc } \\
\text { se); CDS } \\
\text { dit spreac } \\
\text { hing mat! } \\
\text { )); S\&P ( }\end{array}$ & $\begin{array}{l}\text { o 2013Q4. So } \\
\text { cale (1 for AA } \\
\text { gov (5y gover } \\
\text { d); LIBOR-OIS } \\
\text { urity of less th } \\
\text { (agency bank }\end{array}$ & $\begin{array}{l}3 \text { mor } \\
\text { git }\end{array}$ & $\begin{array}{l}\text { o over } \\
\text { loan_g } \\
\text { ernme }\end{array}$ & $\begin{array}{l}\text { h (quar } \\
\text { lift in }\end{array}$ & $\begin{array}{l}\text { p); LiRis } \\
\text { on_quar } \\
\text { merical }\end{array}$ & ratio of cash, & $\begin{array}{l}\text { ody's KMV, Inter } \\
\text { s_d (values: } 0,1 \text { ) } \\
\text { riable with } 1 \text { for } \\
\text { central bank exc } \\
\text { pans to the priva } \\
\text { AA) to } 24(D)) ;\end{array}$ & onal \\
\hline
\end{tabular}


Table 4. Bank Regulatory Capital and Funding Costs

\begin{tabular}{|c|c|c|c|c|c|c|}
\hline & \multicolumn{2}{|c|}{ Specification 1} & \multicolumn{2}{|c|}{ Specification 2} & \multicolumn{2}{|c|}{ Specification 3} \\
\hline & CT1 & FVCDS & $\mathrm{CT} 1$ & FVCDS & $\mathrm{CT} 1$ & FVCDS \\
\hline \multicolumn{7}{|c|}{ Endogenous variables } \\
\hline CT1 & & $\begin{array}{c}-1.048 * * * \\
(0.273)\end{array}$ & & $\begin{array}{c}-1.129^{\star \star \star} \\
(0.235)\end{array}$ & & $\begin{array}{c}-0.848^{* * *} \\
(0.282)\end{array}$ \\
\hline FVCDS & $\begin{array}{c}-0.320 * * * \\
(0.095)\end{array}$ & & $\begin{array}{c}-0.324^{\star \star \star} \\
(0.086)\end{array}$ & & $\begin{array}{c}-0.186 * * * \\
(0.0719)\end{array}$ & \\
\hline$\Delta C T 1^{2}$ _sign & & & & & & $\begin{array}{c}0.0761 \\
(0.0544)\end{array}$ \\
\hline$\triangle \mathrm{FVCDS}^{2}$ _sign & & & & & $\begin{array}{c}-0.00963 \\
(0.0249)\end{array}$ & \\
\hline \multicolumn{7}{|c|}{ Exogenous variables } \\
\hline \multicolumn{7}{|l|}{ Bank specific } \\
\hline LLP & $\begin{array}{c}-1.600 * * * \\
(0.346)\end{array}$ & & $\begin{array}{c}-1.593^{\star \star \star} \\
(0.312)\end{array}$ & & $\begin{array}{c}-1.844^{* * *} \\
(0.386)\end{array}$ & \\
\hline $\mathrm{NI}$ & $\begin{array}{c}-0.144 \\
(0.174)\end{array}$ & $\begin{array}{c}-0.547^{* *} \\
(0.224)\end{array}$ & $\begin{array}{l}-0.141 \\
(0.157)\end{array}$ & $\begin{array}{c}-0.565^{\star \star *} \\
(0.141)\end{array}$ & $\begin{array}{c}-0.104 \\
(0.199)\end{array}$ & $\begin{array}{c}-0.627^{* * *} \\
(0.206)\end{array}$ \\
\hline $\operatorname{S\& P}(\operatorname{lag} 1)$ & & $\begin{array}{c}0.379 * * * \\
(0.127)\end{array}$ & & $\begin{array}{c}0.299 * * * \\
(0.075)\end{array}$ & & $\begin{array}{c}0.326^{* * *} \\
(0.119)\end{array}$ \\
\hline$\Delta \mathrm{CT} 1 \_\mathrm{d}$ & & & $\begin{array}{c}0.078 \\
(0.268)\end{array}$ & & $\begin{array}{l}0.0352 \\
(0.285)\end{array}$ & \\
\hline \multicolumn{7}{|l|}{ Country specific } \\
\hline CDS_gov & & $\begin{array}{c}3.707 * * * \\
(0.613)\end{array}$ & & $\begin{array}{l}4.137^{\star * *} \\
(0.407)\end{array}$ & & $\begin{array}{c}4.073 * * * \\
(0.593)\end{array}$ \\
\hline loan_growth & $\begin{array}{c}0.005 \\
(0.040)\end{array}$ & & $\begin{array}{c}0.005 \\
(0.037)\end{array}$ & & $\begin{array}{c}0.0360 \\
(0.0372)\end{array}$ & \\
\hline \multicolumn{7}{|c|}{ Global variables } \\
\hline LIBOR_OIS & & $\begin{array}{c}0.492 \\
(0.328)\end{array}$ & & $\begin{array}{c}0.0171^{\star \star \star} \\
(0.315)\end{array}$ & & $\begin{array}{c}0.0122 * * * \\
(0.00470)\end{array}$ \\
\hline VIX & & & & $\begin{array}{c}-0.064^{\star \star *} \\
(0.022)\end{array}$ & & $\begin{array}{r}-0.0313 \\
(0.0285)\end{array}$ \\
\hline Crisis_d & $\begin{array}{c}3.230 * * * \\
(0.180)\end{array}$ & $\begin{array}{c}2.264^{* * *} \\
(0.766)\end{array}$ & $\begin{array}{c}3.260 \text { *** } \\
(0.165)\end{array}$ & $\begin{array}{c}2.97142^{\star * \star} \\
(0.782)\end{array}$ & $\begin{array}{c}3.221^{* * *} \\
(0.188)\end{array}$ & $\begin{array}{l}1.676^{*} \\
(0.956)\end{array}$ \\
\hline Constant & $\begin{array}{c}7.466 * * * \\
(0.881)\end{array}$ & $\begin{array}{c}8.123^{* * *} \\
(2.009)\end{array}$ & $\begin{array}{c}7.470^{* * *} \\
(1.007)\end{array}$ & $\begin{array}{c}9.418^{* * *} \\
(2.931)\end{array}$ & $\begin{array}{c}7.001^{* * *} \\
(0.935)\end{array}$ & $\begin{array}{c}7.548 * * * \\
(2.257)\end{array}$ \\
\hline Bank FE & Yes & Yes & Yes & Yes & Yes & Yes \\
\hline $\operatorname{Adj} R^{2}$ & 0.984 & 0.825 & 0.984 & 0.825 & 0.984 & 0.824 \\
\hline Obs & 782 & 782 & 772 & 772 & 772 & 772 \\
\hline McElroy $R^{2}$ & \multicolumn{2}{|c|}{0.896} & \multicolumn{2}{|c|}{0.884} & \multicolumn{2}{|c|}{0.755} \\
\hline \multicolumn{7}{|c|}{$\begin{array}{l}\text { Notes: This table shows that results of estimating the system (1) using } 2 \text { SLS. The table reports the estimated coefficients, t- } \\
\text { statistics, adjusted R2, and McElroy R2. The dependent variables are regulatory capital (CT1) and 5y fair value CDS (FVCDS). The } \\
\text { baseline specification (Specification } 1 \text { ) includes a set of bank specific variables to capture asset quality (LLP), the capacity to } \\
\text { generate organic capital (NI), and the bank rating (S\&P) lagged one period to address endogeneity. Country specific variables } \\
\text { includes the value of sovereign support from implicit guarantees (CDS_gov) and credit growth to the private sector } \\
\text { (loan_growth). Global variables include spreads in money markets (LIBOR-OIS), investor sentiment in equity markets (VIX), and } \\
\text { a dummy for the global financial crisis (Crisis_d). Specification } 2 \text { includes the impact of deliberate management actions to raise } \\
\text { regulatory capital ( } \triangle C T 1 \text { d d). Specification } 3 \text { includes non-linear effects of funding costs (regulatory capital) on regulatory } \\
\text { capital (funding costs). The results are based on quarterly data from 2004Q4 to 2013Q4. }\end{array}$} \\
\hline
\end{tabular}




\begin{tabular}{|c|c|c|c|c|c|c|}
\hline & \multicolumn{2}{|c|}{ Specification 1} & \multicolumn{2}{|c|}{ Specification 2} & \multicolumn{2}{|c|}{ Specification 3} \\
\hline & CT1 & FVCDS & CT1 & FVCDS & CT1 & FVCDS \\
\hline \multicolumn{7}{|c|}{ Qualitity of instruments (HO: Instruments are weak) } \\
\hline F Statistic & 1059.00 & 81.77 & 1020.27 & 78.46 & 989.79 & 76.44 \\
\hline$p$ value & 0.00 & 0.00 & 0.00 & 0.00 & 0.00 & 0.00 \\
\hline \multicolumn{7}{|c|}{ Exogeneity of instruments ( $\mathrm{H} 0: 2 \mathrm{SLS}$ is valid) } \\
\hline J test statistic & 0.55 & 0.08 & 1.02 & 0.13 & 1.25 & 1.06 \\
\hline$p$ value & 0.28 & 0.75 & 0.06 & 0.75 & 0.04 & 0.07 \\
\hline $\begin{array}{l}\text { LMF test } \\
\text { statistic }\end{array}$ & 5.16 & 1.96 & 6.54 & 3.27 & 14.21 & 30.12 \\
\hline $\mathrm{p}$ value & 0.86 & 0.16 & 0.09 & 0.20 & 0.16 & 0.00 \\
\hline \multicolumn{7}{|c|}{ Regression based Hausman for endogeneity of specific variables ( $\mathrm{H}_{0}$ : Specific variables are exogenous) } \\
\hline t value & 6.06 & 7.52 & 6.09 & 5.94 & 6.55 & 5.78 \\
\hline $\mathrm{p}$ value & 0.00 & 0.00 & 0.00 & 0.00 & 0.00 & 0.00 \\
\hline \multicolumn{7}{|c|}{ System Overid Test (provided 2SLS is valid, H0: 2 SLS is preferred to 3SLS) } \\
\hline $\begin{array}{l}\text { Hansen test } \\
\text { statistic }\end{array}$ & \multicolumn{2}{|c|}{31.54} & \multicolumn{2}{|c|}{53.00} & \multicolumn{2}{|c|}{59.58} \\
\hline $\mathrm{p}$ value & \multicolumn{2}{|c|}{0.00} & \multicolumn{2}{|c|}{0.00} & \multicolumn{2}{|c|}{0.00} \\
\hline
\end{tabular}


Table 6. Market-Based Bank Solvency and Funding Costs

\begin{tabular}{|c|c|c|c|c|c|c|}
\hline & \multicolumn{2}{|c|}{ Specification 1} & \multicolumn{2}{|c|}{ Specification 2} & \multicolumn{2}{|c|}{ Specification 3} \\
\hline & EDF & FVCDS & EDF & FVCDS & EDF & FVCDS \\
\hline \multicolumn{7}{|c|}{ Endogenous variables } \\
\hline EDF & & $\begin{array}{c}1.403^{* * *} \\
(0.119)\end{array}$ & & $\begin{array}{c}1.346^{\star * \star} \\
(0.143)\end{array}$ & & $\begin{array}{c}1.644^{* * *} \\
(0.110)\end{array}$ \\
\hline FVCDS & $\begin{array}{c}0.659 * * * \\
(0.0508)\end{array}$ & & $\begin{array}{l}0.588^{* * *} \\
(0.0492)\end{array}$ & & $\begin{array}{c}0.549 * * * \\
(0.0285)\end{array}$ & \\
\hline$\Delta \mathrm{EDF}^{2}$ _sign & & & & & & $\begin{array}{c}0.0440 * * * \\
(0.0160)\end{array}$ \\
\hline$\triangle \mathrm{FVCDS}^{2}$ _sign & & & & & $\begin{array}{l}-0.0164 * \\
(0.00875)\end{array}$ & \\
\hline \multicolumn{7}{|c|}{ Exogenous variables } \\
\hline \multicolumn{7}{|l|}{ Bank specific } \\
\hline LLP & $\begin{array}{l}0.0754 \\
(0.120)\end{array}$ & & $\begin{array}{c}0.190 \\
(0.124)\end{array}$ & & $\begin{array}{c}0.143 \\
(0.123)\end{array}$ & \\
\hline NI & $\begin{array}{c}-0.108 \\
(0.0679)\end{array}$ & $\begin{array}{c}0.123 \\
(0.113)\end{array}$ & $\begin{array}{c}-0.119 \\
(0.0727)\end{array}$ & $\begin{array}{l}0.0675 \\
(0.125)\end{array}$ & $\begin{array}{c}-0.209 * * \\
(0.0823)\end{array}$ & $\begin{array}{c}0.374 * * \\
(0.147)\end{array}$ \\
\hline S\&P & & $\begin{array}{c}0.0244 \\
(0.0346)\end{array}$ & & $\begin{array}{l}0.0865^{*} \\
(0.0449)\end{array}$ & & $\begin{array}{c}0.0559 \\
(0.0379)\end{array}$ \\
\hline$\Delta \mathrm{CT} 1 \_\mathrm{d}$ & & & $\begin{array}{c}-0.00478 \\
(0.0371)\end{array}$ & & $\begin{array}{c}0.0303 \\
(0.0720)\end{array}$ & \\
\hline \multicolumn{7}{|l|}{ Country specific } \\
\hline CDS_gov & & $\begin{array}{c}0.180 \\
(0.266)\end{array}$ & & $\begin{array}{l}0.634^{*} \\
(0.360)\end{array}$ & & $\begin{array}{c}0.187 \\
(0.308)\end{array}$ \\
\hline loan_growth & $\begin{array}{r}-0.00908 \\
(0.0126)\end{array}$ & & $\begin{array}{l}-0.0228^{*} \\
(0.0125)\end{array}$ & & $\begin{array}{l}-0.00360 \\
(0.00926)\end{array}$ & \\
\hline \multicolumn{7}{|l|}{ Global variables } \\
\hline LIBOR_OIS & $\begin{array}{c}-0.0184^{* * *} \\
(0.00126)\end{array}$ & $\begin{array}{c}0.0268 * * * \\
(0.00217)\end{array}$ & $\begin{array}{c}-0.0180^{* * *} \\
(0.00142)\end{array}$ & $\begin{array}{l}0.0268^{* * *} \\
(0.00269)\end{array}$ & $\begin{array}{c}-0.0181 * * * \\
(0.00141)\end{array}$ & $\begin{array}{c}0.0311^{* * *} \\
(0.00290)\end{array}$ \\
\hline VIX & $\begin{array}{l}0.0538^{* * *} \\
(0.00512)\end{array}$ & $\begin{array}{c}-0.0760 * * * \\
(0.0110)\end{array}$ & $\begin{array}{l}0.0557^{* * *} \\
(0.00592)\end{array}$ & $\begin{array}{c}-0.0735^{\star * *} \\
(0.0141)\end{array}$ & $\begin{array}{c}0.0608 * * * \\
(0.00600)\end{array}$ & $\begin{array}{c}-0.101 * * * \\
(0.0137)\end{array}$ \\
\hline Crisis_d & $\begin{array}{c}-0.258 * * * \\
(0.0770)\end{array}$ & $\begin{array}{c}0.360 * * * \\
(0.117)\end{array}$ & $\begin{array}{l}-0.0622 \\
(0.0986)\end{array}$ & $\begin{array}{r}-0.0892 \\
(0.188)\end{array}$ & $\begin{array}{r}-0.0557 \\
(0.103)\end{array}$ & $\begin{array}{c}0.00788 \\
(0.203)\end{array}$ \\
\hline Constant & $\begin{array}{c}-1.039 * * * \\
(0.141)\end{array}$ & $\begin{array}{c}1.396 * * * \\
(0.333)\end{array}$ & $\begin{array}{c}-1.969 * * * \\
(0.430)\end{array}$ & $\begin{array}{c}2.933^{* * *} \\
(0.616)\end{array}$ & $\begin{array}{c}-1.911^{* * *} \\
(0.435)\end{array}$ & $\begin{array}{c}3.225^{* * *} \\
(0.791)\end{array}$ \\
\hline Bank FE & Yes & Yes & Yes & Yes & Yes & Yes \\
\hline Adj $R^{2}$ & 0.782 & 0.774 & 0.785 & 0.776 & 0.771 & 0.559 \\
\hline Obs & 946 & 946 & 773 & 773 & 771 & 771 \\
\hline McElroy $R^{2}$ & \multicolumn{2}{|c|}{0.999} & \multicolumn{2}{|c|}{0.990} & \multicolumn{2}{|c|}{0.723} \\
\hline $\begin{array}{l}\text { Notes: This tabl } \\
\text { adjusted R2, and } \\
\text { by Moody's (EDF } \\
\text { capture asset qua } \\
\text { endogeneity. Cou } \\
\text { the private sector } \\
\text { (VIX), and a dumr } \\
\text { regulatory capital } \\
\text { capital EDF (fund }\end{array}$ & $\begin{array}{l}\text { ws that results } \\
\text { oy R2. The dep } \\
5 y \text { fair value C } \\
\text { LP), the capaci } \\
\text { pecific variabl } \\
\text { growth). Glot } \\
\text { the global fin } \\
\text { 1_d). Specifica } \\
\text { sts). The result }\end{array}$ & $\begin{array}{l}\text { estimating the } \\
\text { dent variables a } \\
\text { (FVCDS). The b } \\
\text { o generate org } \\
\text { cludes the val } \\
\text { /ariables includ } \\
\text { ial crisis (Crisis } \\
3 \text { includes nor } \\
\text { e based on qu }\end{array}$ & $\begin{array}{l}\text { (1) using } 3 \mathrm{SL} \\
\text { rket-based cap } \\
\text { specification } \\
\text { pital (NI), and } \\
\text { overeign supp } \\
\text { ads in money n } \\
\text { ecification } 2 \text { inc } \\
\text { effects of func } \\
\text { data from } 200\end{array}$ & $\begin{array}{l}\text { e table repor } \\
\text { proxied by the } \\
\text { cification } 1 \text { ) ir } \\
\text { bank rating (S } \\
\text { rom implicit } 9 \\
\text { ets (LIBOR-OI } \\
\text { es the impact } \\
\text { costs (marke } \\
\text { to 2013Q4. }\end{array}$ & $\begin{array}{l}\text { imated coefficie } \\
\text { cted default frec } \\
\text { set of bank spe } \\
\text { ed one period t } \\
s \text { (CDS_gov) anc } \\
\text { or sentiment in } \\
\text { rate manageme } \\
\text { apital EDF) on n }\end{array}$ & $\begin{array}{l}\text { S, t-statistics, } \\
\text { ency estimated } \\
\text { c variables to } \\
\text { ddress } \\
\text { redit growth to } \\
\text { uity markets } \\
\text { actions to raise } \\
\text { ket-based }\end{array}$ \\
\hline
\end{tabular}




\section{Table 7. Test Results for Market-Based Bank Solvency and Funding Costs}

\begin{tabular}{|c|c|c|c|c|c|c|}
\hline & \multicolumn{2}{|c|}{ Specification 1} & \multicolumn{2}{|c|}{ Specification 2} & \multicolumn{2}{|c|}{ Specification 3} \\
\hline & EDF & FVCDS & EDF & FVCDS & EDF & FVCDS \\
\hline \multicolumn{7}{|c|}{ Qualitity of instruments (HO: Instruments are weak) } \\
\hline F Statistic & 41.38 & 97.37 & 33.81 & 83.95 & 33.75 & 92.36 \\
\hline$p$ value & 0.00 & 0.00 & 0.00 & 0.00 & 0.00 & 0.00 \\
\hline \multicolumn{7}{|c|}{ Exogeneity of instruments ( $\mathrm{HO}: 2 \mathrm{SLS}$ is valid) } \\
\hline $\begin{array}{l}\text { J test } \\
\text { statistic }\end{array}$ & 0.01 & 0.10 & 0.03 & 0.16 & 0.86 & 0.77 \\
\hline$p$ value & 0.96 & 0.66 & 0.88 & 0.69 & 0.13 & 0.27 \\
\hline $\begin{array}{l}\text { LMF test } \\
\text { statistic }\end{array}$ & 0.11 & 2.51 & 0.27 & 3.97 & 9.74 & 21.72 \\
\hline$p$ value & 0.74 & 0.11 & 0.60 & 0.14 & 0.28 & 0.01 \\
\hline
\end{tabular}

Regression based Hausman for endogeneity of specific variables ( $\mathrm{HO}$ : Specific variables are exogenous)

$\begin{array}{lllllll}\mathrm{t} \text { value } & -1.83 & -3.87 & -0.25 & -2.95 & 3.89 & -3.44 \\ \mathrm{p} \text { value } & 0.07 & 0.00 & 0.80 & 0.00 & 0.00 & 0.00\end{array}$

System Overid Test (provided 2SLS is valid, H0: 2SLS is preferred to 3SLS)

Hansen test

statistic

4.96

5.88

0.01

$p$ value

0.17

0.21

0.99

Notes: This table shows that the various specification tests for the results shown in Table 6 . We check for the quality of instruments (F-test) and the exogeneity of instruments (J-test and Lagrange multiplier test). We test the endogeneity of the RHS endogenous variables ( $t$-test) and we apply the Hansen system overidentification test. 


\section{Table 8. Bank Regulatory Capital and Funding Costs (Controlling for Liquidity Risk)}

\begin{tabular}{|c|c|c|c|c|c|c|}
\hline & \multicolumn{2}{|c|}{ Specification 1} & \multicolumn{2}{|c|}{ Specification 2} & \multicolumn{2}{|c|}{ Specification 3} \\
\hline & CT1 & FVCDS & CT1 & FVCDS & СT1 & FVCDS \\
\hline \multicolumn{7}{|c|}{ Endogenous variables } \\
\hline CT1 & & $\begin{array}{c}-1.028^{* * *} \\
(0.251)\end{array}$ & & $\begin{array}{c}-1.055^{\star \star *} \\
(0.342)\end{array}$ & & $\begin{array}{c}-0.939 * * * \\
(0.270)\end{array}$ \\
\hline FVCDS & $\begin{array}{c}-0.350 * * * \\
(0.0975)\end{array}$ & & $\begin{array}{c}-0.390 \text { *** } \\
(0.101)\end{array}$ & & $\begin{array}{c}-0.219 * * * \\
(0.0713)\end{array}$ & \\
\hline$\Delta \mathrm{CT} 1^{2}$ _sign & & & & & & $\begin{array}{c}0.0835 \\
(0.0551)\end{array}$ \\
\hline$\triangle \mathrm{FVCDS}^{2}{ }_{-}$sign & & & & & $\begin{array}{l}-0.0125 \\
(0.0250)\end{array}$ & \\
\hline \multicolumn{7}{|c|}{ Exogenous variables } \\
\hline \multicolumn{7}{|l|}{ Bank specific } \\
\hline LLP & $\begin{array}{c}-1.476^{* * *} \\
(0.341)\end{array}$ & & $\begin{array}{c}-1.432^{\star * \star} \\
(0.348)\end{array}$ & & $\begin{array}{c}-1.746^{* * *} \\
(0.385)\end{array}$ & \\
\hline NI & $\begin{array}{c}-0.194 \\
(0.173)\end{array}$ & $\begin{array}{c}-0.578^{* * *} \\
(0.211)\end{array}$ & $\begin{array}{l}-0.209 \\
(0.177)\end{array}$ & $\begin{array}{c}-0.587^{* * *} \\
(0.215)\end{array}$ & $\begin{array}{r}-0.168 \\
(0.201)\end{array}$ & $\begin{array}{c}-0.635^{* * *} \\
(0.208)\end{array}$ \\
\hline S\&P (lag 1) & & $\begin{array}{c}0.281^{* *} \\
(0.112)\end{array}$ & & $\begin{array}{l}0.236^{\star \star} \\
(0.110)\end{array}$ & & $\begin{array}{c}0.293^{* *} \\
(0.116)\end{array}$ \\
\hline LiRisk & & $\begin{array}{l}0.0961^{* *} \\
(0.0434)\end{array}$ & & $\begin{array}{l}0.0998^{* *} \\
(0.0498)\end{array}$ & & $\begin{array}{c}0.0693 \\
(0.0450)\end{array}$ \\
\hline$\Delta C T 1$ d & & & $\begin{array}{c}0.158 \\
(0.309)\end{array}$ & & $\begin{array}{l}0.0712 \\
(0.291)\end{array}$ & \\
\hline \multicolumn{7}{|l|}{ Country specific } \\
\hline CDS_gov & & $\begin{array}{c}4.154 * * * \\
(0.662)\end{array}$ & & $\begin{array}{l}4.464^{* * *} \\
(0.711)\end{array}$ & & $\begin{array}{c}4.465^{* * *} \\
(0.685)\end{array}$ \\
\hline loan_growth & $\begin{array}{c}-0.000355 \\
(0.0407)\end{array}$ & & $\begin{array}{c}-0.00987 \\
(0.0418)\end{array}$ & & $\begin{array}{c}0.0282 \\
(0.0372)\end{array}$ & \\
\hline \multicolumn{7}{|l|}{ Global variables } \\
\hline LIBOR_OIS & & $\begin{array}{l}0.0045 \\
(0.303)\end{array}$ & & $\begin{array}{c}0.0117^{\star \star} \\
(0.460)\end{array}$ & & $\begin{array}{c}0.00766 \\
(0.00475)\end{array}$ \\
\hline VIX & & & & $\begin{array}{l}-0.0360 \\
(0.0312)\end{array}$ & & $\begin{array}{r}-0.0158 \\
(0.0269)\end{array}$ \\
\hline Crisis_d & $\begin{array}{c}3.254^{* * *} \\
(0.177)\end{array}$ & $\begin{array}{c}2.386 * * * \\
(0.776)\end{array}$ & $\begin{array}{c}3.287^{* \star *} \\
(0.184)\end{array}$ & $\begin{array}{l}2.715^{\star *} \\
(1.201)\end{array}$ & $\begin{array}{c}3.236 * * * \\
(0.186)\end{array}$ & $\begin{array}{l}1.846^{*} \\
(0.980)\end{array}$ \\
\hline Constant & $\begin{array}{c}7.550^{* * *} \\
(0.864)\end{array}$ & $\begin{array}{c}8.146 * * * \\
(1.848)\end{array}$ & $\begin{array}{c}7.693^{* * *} \\
(1.002)\end{array}$ & $\begin{array}{c}8.840 * * * \\
(2.569)\end{array}$ & $\begin{array}{c}7.119 * * * \\
(0.918)\end{array}$ & $\begin{array}{c}8.122^{* * *} \\
(2.162)\end{array}$ \\
\hline Bank FE & Yes & Yes & Yes & Yes & Yes & Yes \\
\hline $\operatorname{Adj} R^{2}$ & 0.987 & 0.845 & 0.987 & 0.846 & & \\
\hline Obs & 742 & 742 & 732 & 732 & 732 & 732 \\
\hline McElroy $R^{2}$ & & & & & & \\
\hline
\end{tabular}

Notes: This table shows that results of estimating the system (1) using 2 SLS. The table reports the estimated coefficients, tstatistics, adjusted R2, and McElroy R2. The dependent variables are regulatory capital (CT1) and 5y fair value CDS (FVCDS). The baseline specification (Specification 1) includes a set of bank specific variables to capture asset quality (LLP), the capacity to generate organic capital (NI), the bank rating (S\&P) lagged one period, and liquidity risk bearing capacity (LiRisk). Country specific variables includes the value of sovereign support from implicit guarantees (CDS_gov) and credit growth to the private sector (loan_growth). Global variables include spreads in money markets (LIBOR-OIS), investor sentiment in equity markets (VIX), and a dummy for the global financial crisis (Crisis_d). Specification 2 includes the impact of deliberate management actions to raise regulatory capital $\left(\triangle C T 1_{-} d\right.$ ). Specification 3 includes non-linear effects of funding costs (regulatory capital) on regulatory capital (funding costs). The results are based on quarterly data from 2004Q4 to $2013 \mathrm{Q} 4$. 


\begin{tabular}{|c|c|c|c|c|c|c|}
\hline \multicolumn{7}{|c|}{$\begin{array}{r}\text { Table 9. Test Results fo } \\
\text { (Co }\end{array}$} \\
\hline & \multicolumn{2}{|c|}{ Specification 1} & \multicolumn{2}{|c|}{ Specification 2} & \multicolumn{2}{|c|}{ Specification 3} \\
\hline & CT1 & FVCDS & CT1 & FVCDS & CT1 & FVCDS \\
\hline \multicolumn{7}{|c|}{ Qualitity of instruments (HO: Instruments are weak) } \\
\hline F Statistic & 1109.04 & 85.79 & 1072.10 & 82.85 & 1036.92 & 82.09 \\
\hline$p$ value & 0.00 & 0.00 & 0.00 & 0.00 & 0.00 & 0.00 \\
\hline \multicolumn{7}{|c|}{ Exogeneity of instruments ( $\mathrm{HO}: 2 \mathrm{SLS}$ is valid) } \\
\hline J test statistic & 0.73 & 0.06 & 0.93 & 0.10 & 0.95 & 1.04 \\
\hline $\mathrm{p}$ value & 0.21 & 0.77 & 0.10 & 0.80 & 0.17 & 0.05 \\
\hline $\begin{array}{l}\text { LMF test } \\
\text { statistic }\end{array}$ & 6.73 & 1.49 & 8.99 & 2.37 & 10.45 & 28.41 \\
\hline$p$ value & 0.08 & 0.22 & 0.06 & 0.31 & 0.40 & 0.00 \\
\hline \multicolumn{7}{|c|}{ Regression based Hausman for endogeneity of specific variables (H0: Specific variables are exogenous) } \\
\hline $\mathrm{t}$ value & 5.59 & 7.43 & 6.03 & 5.77 & 6.46 & 6.65 \\
\hline$p$ value & 0.00 & 0.00 & 0.00 & 0.00 & 0.00 & 0.00 \\
\hline \multicolumn{7}{|c|}{ System Overid Test (provided 2SLS is valid, H0: 2SLS is preferred to 3SLS) } \\
\hline $\begin{array}{l}\text { Hansen test } \\
\text { statistic }\end{array}$ & \multicolumn{2}{|c|}{41.99} & \multicolumn{2}{|c|}{49.23} & \multicolumn{2}{|c|}{53.06} \\
\hline$p$ value & \multicolumn{2}{|c|}{0.00} & \multicolumn{2}{|c|}{0.00} & \multicolumn{2}{|c|}{0.00} \\
\hline
\end{tabular}


Table 10. Market-Based Bank Solvency and Funding Costs (Controlling for Liquidity Risk)

\begin{tabular}{|c|c|c|c|c|c|c|}
\hline & \multicolumn{2}{|c|}{ Specification 1} & \multicolumn{2}{|c|}{ Specification 2} & \multicolumn{2}{|c|}{ Specification 3} \\
\hline & EDF & FVCDS & EDF & FVCDS & EDF & FVCDS \\
\hline \multicolumn{7}{|c|}{ Endogenous variables } \\
\hline EDF & & $\begin{array}{c}1.372 * * * \\
(0.123)\end{array}$ & & $\begin{array}{c}1.276^{* * *} \\
(0.148)\end{array}$ & & $\begin{array}{c}1.731^{* * *} \\
(0.110)\end{array}$ \\
\hline FVCDS & $\begin{array}{c}0.687 * * * \\
(0.0559)\end{array}$ & & $\begin{array}{l}0.613^{* * *} \\
(0.0528)\end{array}$ & & $\begin{array}{c}0.553 * * * \\
(0.0272)\end{array}$ & \\
\hline$\Delta \mathrm{EDF}^{2}$ _sign & & & & & & $\begin{array}{c}0.0420 * * \\
(0.0164)\end{array}$ \\
\hline$\triangle \mathrm{FVCDS}^{2}{ }_{-}$sign & & & & & $\begin{array}{c}-0.0196 * * \\
(0.00948)\end{array}$ & \\
\hline \multicolumn{7}{|c|}{ Exogenous variables } \\
\hline \multicolumn{7}{|l|}{ Bank specific } \\
\hline LLP & $\begin{array}{l}0.0551 \\
(0.124)\end{array}$ & & $\begin{array}{c}0.194 \\
(0.129)\end{array}$ & & $\begin{array}{l}0.0542 \\
(0.119)\end{array}$ & \\
\hline NI & $\begin{array}{c}-0.0951 \\
(0.0705)\end{array}$ & $\begin{array}{c}0.108 \\
(0.115)\end{array}$ & $\begin{array}{c}-0.104 \\
(0.0755)\end{array}$ & $\begin{array}{l}0.0290 \\
(0.127)\end{array}$ & $\begin{array}{c}-0.238^{* * *} \\
(0.0871)\end{array}$ & $\begin{array}{c}0.423 * * * \\
(0.157)\end{array}$ \\
\hline$S \& P$ & & $\begin{array}{c}0.0166 \\
(0.0330)\end{array}$ & & $\begin{array}{l}0.0835^{\star} \\
(0.0426)\end{array}$ & & $\begin{array}{c}0.0391 \\
(0.0345)\end{array}$ \\
\hline LiRisk & & $\begin{array}{r}-0.000471 \\
(0.00149)\end{array}$ & & $\begin{array}{c}-0.000592 \\
(0.00405)\end{array}$ & & $\begin{array}{c}-0.000666 \\
(0.0103)\end{array}$ \\
\hline$\Delta C T 1 \_d$ & & & $\begin{array}{c}0.0180 \\
(0.0434)\end{array}$ & & $\begin{array}{c}0.0231 \\
(0.0701)\end{array}$ & \\
\hline \multicolumn{7}{|c|}{ Country specific } \\
\hline CDS_gov & & $\begin{array}{c}0.142 \\
(0.302)\end{array}$ & & $\begin{array}{l}0.749^{*} \\
(0.431)\end{array}$ & & $\begin{array}{r}-0.0972 \\
(0.363)\end{array}$ \\
\hline loan_growth & $\begin{array}{r}-0.00660 \\
(0.0128)\end{array}$ & & $\begin{array}{l}-0.0221^{*} \\
(0.0121)\end{array}$ & & $\begin{array}{c}-0.00272 \\
(0.00871)\end{array}$ & \\
\hline \multicolumn{7}{|c|}{ Global variables } \\
\hline LIBOR_OIS & $\begin{array}{c}-0.0181^{* * *} \\
(0.00124)\end{array}$ & $\begin{array}{c}0.0254^{* * *} \\
(0.00234)\end{array}$ & $\begin{array}{c}-0.0179^{* * *} \\
(0.00140)\end{array}$ & $\begin{array}{l}0.0245^{\star * *} \\
(0.00290)\end{array}$ & $\begin{array}{c}-0.0181 * * * \\
(0.00146)\end{array}$ & $\begin{array}{c}0.0318^{* * *} \\
(0.00315)\end{array}$ \\
\hline VIX & $\begin{array}{l}0.0507^{* * *} \\
(0.00540)\end{array}$ & $\begin{array}{c}-0.0692^{* * *} \\
(0.0118)\end{array}$ & $\begin{array}{l}0.0529^{\star * *} \\
(0.00636)\end{array}$ & $\begin{array}{c}-0.0624^{* * *} \\
(0.0152)\end{array}$ & $\begin{array}{c}0.0613^{* * *} \\
(0.00638)\end{array}$ & $\begin{array}{c}-0.106 * * * \\
(0.0148)\end{array}$ \\
\hline \multirow[t]{2}{*}{ Crisis_d } & $\begin{array}{c}-0.264 * * * \\
(0.0776)\end{array}$ & $\begin{array}{c}0.355^{* * *} \\
(0.122)\end{array}$ & $\begin{array}{l}-0.0583 \\
(0.0992)\end{array}$ & $\begin{array}{l}-0.147 \\
(0.200)\end{array}$ & $\begin{array}{r}-0.0574 \\
(0.106)\end{array}$ & $\begin{array}{l}0.0600 \\
(0.216)\end{array}$ \\
\hline & $\begin{array}{c}-1.032^{* * *} \\
(0.141)\end{array}$ & $\begin{array}{c}1.369 * * * \\
(0.335)\end{array}$ & $\begin{array}{c}-2.026^{* * *} \\
(0.437)\end{array}$ & $\begin{array}{c}2.894 * * * \\
(0.595)\end{array}$ & $\begin{array}{c}-1.919 * * * \\
(0.446)\end{array}$ & $\begin{array}{c}3.335^{* * *} \\
(0.823)\end{array}$ \\
\hline Bank FE & Yes & Yes & Yes & Yes & Yes & Yes \\
\hline $\operatorname{Adj} R^{2}$ & 0.782 & 0.775 & 0.786 & 0.787 & 0.769 & 0.671 \\
\hline Obs & 905 & 905 & 733 & 733 & 733 & 733 \\
\hline McElroy $\mathrm{R}^{2}$ & \multicolumn{2}{|c|}{0.999} & \multicolumn{2}{|c|}{0.990} & \multicolumn{2}{|c|}{0.760} \\
\hline
\end{tabular}

Notes: This table shows that results of estimating the system (1) using 3 SLS. The table reports the estimated coefficients, t-statistics, adjusted R2, and McElroy R2. The dependent variables are market-based capital proxied by the 5y expected default frequency estimated by Moody's (EDF) and 5y fair value CDS (FVCDS). The baseline specification (Specification 1) includes a set of bank specific variables to capture asset quality (LLP), the capacity to generate organic capital (NI), the bank rating (S\&P), and liquidity risk bearing capacity (LiRisk). Country specific variables includes the value of sovereign support from implicit guarantees (CDS_gov) and credit growth to the private sector (loan_growth). Global variables include spreads in money markets (LIBOR-OIS), investor sentiment in equity markets (VIX), and a dummy for the global financial crisis (Crisis_d). Specification 2 includes the impact of deliberate management actions to raise regulatory capital ( $\triangle C T 1$ 1 d). Specification 3 includes non-linear effects of funding costs (market-based capital EDF) on market-based capital EDF (funding costs). The results are based on quarterly data from 2004Q4 to 2013Q4. 


\begin{tabular}{|c|c|c|c|c|c|c|}
\hline \multicolumn{7}{|c|}{$\begin{array}{l}\text { Table 11. Test Results for Market-Based Bank Solvency and Funding Costs } \\
\text { (Controlling for Liquidity Risk) }\end{array}$} \\
\hline & \multicolumn{2}{|c|}{ Specification 1} & \multicolumn{2}{|c|}{ Specification 2} & \multicolumn{2}{|c|}{ Specification 3} \\
\hline & EDF & FVCDS & EDF & FVCDS & EDF & FVCDS \\
\hline \multicolumn{7}{|c|}{ Qualitity of instruments (HO: Instruments are weak) } \\
\hline F Statistic & 42.01 & 101.93 & 34.32 & 88.64 & 34.49 & 101.90 \\
\hline$p$ value & 0.00 & 0.00 & 0.00 & 0.00 & 0.00 & 0.00 \\
\hline \multicolumn{7}{|c|}{ Exogeneity of instruments ( $\mathrm{HO}: 2 \mathrm{SLS}$ is valid) } \\
\hline J test statistic & 0.02 & 0.12 & 0.04 & 0.15 & 0.80 & 0.71 \\
\hline$p$ value & 0.98 & 0.59 & 0.93 & 0.67 & 0.21 & 0.31 \\
\hline $\begin{array}{l}\text { LMF test } \\
\text { statistic }\end{array}$ & 0.20 & 2.72 & 0.41 & 3.70 & 9.05 & 20.18 \\
\hline p value & 0.90 & 0.10 & 0.81 & 0.16 & 0.53 & 0.03 \\
\hline \multicolumn{7}{|c|}{ Regression based Hausman for endogeneity of specific variables (H0: Specific variables are exogenous) } \\
\hline $\mathrm{t}$ value & -1.89 & -4.02 & -0.32 & -2.78 & 4.79 & -5.24 \\
\hline $\mathrm{p}$ value & 0.06 & 0.00 & 0.75 & 0.01 & 0.00 & 0.00 \\
\hline \multicolumn{7}{|c|}{ System Overid Test (provided 2SLS is valid, H0: 2SLS is preferred to 3SLS) } \\
\hline $\begin{array}{l}\text { Hansen test } \\
\text { statistic }\end{array}$ & \multicolumn{2}{|c|}{5.73} & \multicolumn{2}{|c|}{4.85} & \multicolumn{2}{|c|}{0.66} \\
\hline $\mathrm{p}$ value & \multicolumn{2}{|c|}{0.22} & \multicolumn{2}{|c|}{0.43} & \multicolumn{2}{|c|}{0.98} \\
\hline
\end{tabular}

Notes: This table shows that the various specification tests for the results shown in Table 9. We check for the quality of instruments (F-test) and the exogeneity of instruments (J-test and Lagrange multiplier test). We test the endogeneity of the RHS endoaenous variables (t-test) and we applv the Hansen svstem overidentification test. 
Table 12. Bank Regulatory Capital and Funding Costs (OLS Estimation)

\begin{tabular}{|c|c|c|c|c|c|c|}
\hline & \multicolumn{2}{|c|}{ Specification 1} & \multicolumn{2}{|c|}{ Specification 2} & \multicolumn{2}{|c|}{ Specification 3} \\
\hline & $\mathrm{CT} 1$ & FVCDS & $\mathrm{CT} 1$ & FVCDS & $\mathrm{CT} 1$ & FVCDS \\
\hline \multicolumn{7}{|c|}{ Endogenous variables } \\
\hline \multirow[t]{2}{*}{ СT1 } & & $0.173^{* * *}$ & & $0.209^{\star * *}$ & & $0.215^{* * *}$ \\
\hline & & $(0.0366)$ & & $(0.0376)$ & & $(0.0382)$ \\
\hline \multirow[t]{2}{*}{ FVCDS } & $0.141^{* * *}$ & & $0.145^{\star \star *}$ & & $0.171^{* * *}$ & \\
\hline & $(0.0344)$ & & $(0.0347)$ & & $(0.0372)$ & \\
\hline \multirow[t]{2}{*}{$\Delta \mathrm{CT}^{2}{ }_{\text {__sign }}$} & & & & & & -0.00588 \\
\hline & & & & & & $(0.00628)$ \\
\hline \multirow[t]{2}{*}{$\triangle \mathrm{FVCDS}^{2}$ _sign } & & & & & $-0.0153^{*}$ & \\
\hline & & & & & $(0.00791)$ & \\
\hline \multicolumn{7}{|c|}{ Exogenous variables } \\
\hline \multicolumn{7}{|l|}{ Bank specific } \\
\hline \multirow[t]{2}{*}{ LLP } & $-2.224 * * *$ & & $-2.197^{\star \star \star}$ & & $-2.348^{* * *}$ & \\
\hline & $(0.291)$ & & $(0.295)$ & & $(0.304)$ & \\
\hline \multirow[t]{2}{*}{ NI } & 0.148 & $-0.728 * * *$ & 0.148 & $-0.703^{* * *}$ & 0.0870 & $-0.702 * * *$ \\
\hline & $(0.148)$ & (0.139) & $(0.149)$ & $(0.138)$ & $(0.152)$ & $(0.138)$ \\
\hline \multirow[t]{2}{*}{ S\&P (lag 1) } & & 0.0510 & & $0.123^{*}$ & & $0.117^{*}$ \\
\hline & & $(0.0661)$ & & $(0.0682)$ & & $(0.0685)$ \\
\hline \multirow[t]{2}{*}{$\Delta C T 1 \_d$} & & & -0.106 & & -0.0988 & \\
\hline & & & $(0.266)$ & & $(0.265)$ & \\
\hline \multicolumn{7}{|c|}{ Country specific } \\
\hline \multirow[t]{2}{*}{ CDS_gov } & & $3.959 * * *$ & & $3.623^{* * *}$ & & $3.617^{* * *}$ \\
\hline & & $(0.385)$ & & $(0.395)$ & & $(0.395)$ \\
\hline \multirow[t]{2}{*}{ loan_growth } & $0.129 * * *$ & & $0.131^{\star \star \star}$ & & $0.128^{* * *}$ & \\
\hline & $(0.0295)$ & & $(0.0297)$ & & $(0.0297)$ & \\
\hline \multicolumn{7}{|l|}{ Global variables } \\
\hline \multirow[t]{2}{*}{ LIBOR_OIS } & & $1.571^{* * *}$ & & $0.0077^{\star \star \star}$ & & $0.0078^{* * *}$ \\
\hline & & $(0.143)$ & & $(0.269)$ & & $(0.269)$ \\
\hline \multirow[t]{2}{*}{ VIX } & & & & $0.0446^{* * *}$ & & $0.0443 * * *$ \\
\hline & & & & $(0.0121)$ & & $(0.0121)$ \\
\hline \multirow[t]{2}{*}{ Crisis_d } & $3.159^{* * *}$ & $-0.782^{* * *}$ & $3.212^{\star \star \star}$ & $-1.271^{\star \star \star}$ & $3.170^{* * *}$ & $-1.260 * * *$ \\
\hline & $(0.161)$ & $(0.238)$ & $(0.165)$ & $(0.269)$ & $(0.166)$ & $(0.270)$ \\
\hline \multirow[t]{2}{*}{ Constant } & $5.826^{* * *}$ & 1.002 & $5.705^{* * *}$ & 0.611 & $5.687^{* * *}$ & 0.571 \\
\hline & $(0.740)$ & $(0.800)$ & $(0.850)$ & (0.909) & (0.849) & $(0.910)$ \\
\hline Bank FE & Yes & No & No & No & No & No \\
\hline Adj $R^{2}$ & 0.781 & 0.544 & 0.779 & 0.555 & 0.780 & 0.555 \\
\hline Obs & 782 & 782 & 772 & 772 & 772 & 772 \\
\hline McElroy $R^{2}$ & \multicolumn{2}{|c|}{0.999} & \multicolumn{2}{|c|}{0.990} & \multicolumn{2}{|c|}{0.760} \\
\hline
\end{tabular}

Notes: This table shows that results of estimating the system (1) using OLS. The table reports the estimated coefficients, tstatistics, adjusted R2, and McElroy R2. The dependent variables are regulatory capital (CT1) and 5y fair value CDS (FVCDS). The baseline specification (Specification 1) includes a set of bank specific variables to capture asset quality (LLP), the capacity to generate organic capital (NI), and the bank rating (S\&P) lagged one period to address endogeneity. Country specific variables includes the value of sovereign support from implicit guarantees (CDS_gov) and credit growth to the private sector

(loan_growth). Global variables include spreads in money markets (LIBOR-OIS), investor sentiment in equity markets (VIX), and a dummy for the global financial crisis (Crisis_d). Specification 2 includes the impact of deliberate management actions to raise regulatory capital $(\triangle C T 1$ d). Specification 3 includes non-linear effects of funding costs (regulatory capital) on regulatory capital (funding costs). The results are based on quarterly data from 2004Q4 to $2013 \mathrm{Q} 4$. 
Table 13. Market-Based Bank Solvency and Funding Costs (OLS Estimation)

\begin{tabular}{|c|c|c|c|c|c|c|}
\hline & \multicolumn{2}{|c|}{ Specification 1} & \multicolumn{2}{|c|}{ Specification 2} & \multicolumn{2}{|c|}{ Specification 3} \\
\hline & EDF & FVCDS & EDF & FVCDS & EDF & FVCDS \\
\hline \multicolumn{7}{|c|}{ Endogenous variables } \\
\hline \multirow[t]{2}{*}{ EDF } & & $0.994 * * *$ & & $0.971^{\star * *}$ & & $1.026 * * *$ \\
\hline & & $(0.0279)$ & & $(0.0299)$ & & $(0.0330)$ \\
\hline \multirow[t]{2}{*}{ FVCDS } & $0.591 * * *$ & & $0.607^{* \star \star}$ & & $0.610 * * *$ & \\
\hline & $(0.0163)$ & & $(0.0181)$ & & $(0.0195)$ & \\
\hline \multirow[t]{2}{*}{$\Delta \mathrm{EDF}^{2}$ _sign } & & & & & & $-0.0173 * * *$ \\
\hline & & & & & & $(0.00430)$ \\
\hline \multirow[t]{2}{*}{$\triangle \mathrm{FVCDS}^{2}$ _sign } & & & & & -0.00185 & \\
\hline & & & & & $(0.00397)$ & \\
\hline
\end{tabular}

\begin{tabular}{|c|c|c|c|c|c|c|}
\hline \multicolumn{7}{|c|}{ Exogenous variables } \\
\hline \multicolumn{7}{|c|}{ Bank specific } \\
\hline LLP & $\begin{array}{c}0.351^{* *} \\
(0.141)\end{array}$ & & $\begin{array}{l}0.351^{* *} \\
(0.155)\end{array}$ & & $\begin{array}{c}0.333^{* *} \\
(0.160)\end{array}$ & \\
\hline NI & $\begin{array}{c}-0.101 \\
(0.0687)\end{array}$ & $\begin{array}{c}-0.114 \\
(0.0839)\end{array}$ & $\begin{array}{l}-0.0782 \\
(0.0753)\end{array}$ & $\begin{array}{c}-0.149^{*} \\
(0.0897)\end{array}$ & $\begin{array}{c}-0.0856 \\
(0.0771)\end{array}$ & $\begin{array}{l}-0.174^{*} \\
(0.0889)\end{array}$ \\
\hline S\&P & & $\begin{array}{c}0.0984^{* *} \\
(0.0384)\end{array}$ & & $\begin{array}{l}0.179 * \star * \\
(0.0428)\end{array}$ & & $\begin{array}{c}0.168 * * * \\
(0.0424)\end{array}$ \\
\hline$\Delta C T 1 \_d$ & & & $\begin{array}{c}0.215 \\
(0.143)\end{array}$ & & $\begin{array}{c}0.218 \\
(0.143)\end{array}$ & \\
\hline \multicolumn{7}{|c|}{ Country specific } \\
\hline CDS_gov & & $\begin{array}{c}0.938 * * * \\
(0.222)\end{array}$ & & $\begin{array}{c}1.374^{\star \star *} \\
(0.262)\end{array}$ & & $\begin{array}{c}1.323^{* * *} \\
(0.261)\end{array}$ \\
\hline loan_growth & $\begin{array}{r}-0.00203 \\
(0.0141)\end{array}$ & & $\begin{array}{l}0.00406 \\
(0.0154)\end{array}$ & & $\begin{array}{l}0.00371 \\
(0.0155)\end{array}$ & \\
\hline \multicolumn{7}{|c|}{ Global variables } \\
\hline LIBOR_OIS & $\begin{array}{c}-0.0177^{\star * *} \\
(0.115)\end{array}$ & $\begin{array}{c}0.0218 * * * \\
(0.150)\end{array}$ & $\begin{array}{c}-0.0188^{* * *} \\
(0.142)\end{array}$ & $\begin{array}{c}0.0216^{\star * *} \\
(0.176)\end{array}$ & $\begin{array}{c}-0.0188^{* * *} \\
(0.142)\end{array}$ & $\begin{array}{c}0.0222 * * * \\
(0.176)\end{array}$ \\
\hline VIX & $\begin{array}{l}0.0539^{* * *} \\
(0.00517)\end{array}$ & $\begin{array}{c}-0.0471^{* * *} \\
(0.00682)\end{array}$ & $\begin{array}{l}0.0565^{\star \star *} \\
(0.00612)\end{array}$ & $\begin{array}{c}-0.0419^{* * *} \\
(0.00784)\end{array}$ & $\begin{array}{c}0.0565^{* * *} \\
(0.00614)\end{array}$ & $\begin{array}{c}-0.0450^{* * *} \\
(0.00781)\end{array}$ \\
\hline Crisis_d & $\begin{array}{c}-0.186^{* * *} \\
(0.0689)\end{array}$ & $\begin{array}{c}0.231^{* *} \\
(0.102)\end{array}$ & $\begin{array}{l}-0.0636 \\
(0.0998)\end{array}$ & $\begin{array}{c}-0.327^{\star *} \\
(0.155)\end{array}$ & $\begin{array}{c}-0.0704 \\
(0.101)\end{array}$ & $\begin{array}{c}-0.318^{* *} \\
(0.153)\end{array}$ \\
\hline Constant & $\begin{array}{c}-1.027^{* * *} \\
(0.136)\end{array}$ & $\begin{array}{c}0.605^{* *} \\
(0.256)\end{array}$ & $\begin{array}{c}-2.086^{* * *} \\
(0.427)\end{array}$ & $\begin{array}{c}2.374 * * * \\
(0.560)\end{array}$ & $\begin{array}{c}-2.088^{* * *} \\
(0.428)\end{array}$ & $\begin{array}{c}2.447^{* * *} \\
(0.554)\end{array}$ \\
\hline Bank FE & Yes & Yes & Yes & Yes & Yes & Yes \\
\hline Adj $R^{2}$ & 0.787 & 0.818 & 0.787 & 0.816 & 0.787 & 0.821 \\
\hline Obs & 946 & 946 & 773 & 773 & 771 & 771 \\
\hline McElroy $R^{2}$ & & & & & & \\
\hline
\end{tabular}

Notes: This table shows that results of estimating the system (1) using OLS. The table reports the estimated coefficients, t-statistics, adjusted R2, and McElroy R2. The dependent variables are market-based capital proxied by the 5y expected default frequency estimated by Moody's (EDF) and 5y fair value CDS (FVCDS). The baseline specification (Specification 1) includes a set of bank specific variables to capture asset quality (LLP), the capacity to generate organic capital (NI), and the bank rating (S\&P) lagged one period to address endogeneity. Country specific variables includes the value of sovereign support from implicit guarantees (CDS_gov) and credit growth to the private sector (loan_growth). Global variables include spreads in money markets (LIBOR-OIS), investor sentiment in equity markets (VIX), and a dummy for the global financial crisis (Crisis_d). Specification 2 includes the impact of deliberate management actions to raise regulatory capital $\left(\triangle C T 1_{1}\right.$ d). Specification 3 includes non-linear effects of funding costs (market-based capital EDF) on market-based capital EDF (funding costs). The results are based on quarterly data from 2004Q4 to 2013 Q4. 


\begin{tabular}{|c|c|c|c|c|c|c|c|c|c|}
\hline \multicolumn{10}{|c|}{$\begin{array}{l}\text { Table 14. Impact of Bank Solvency and Funding Cost Interaction-2014 EBA Stress Test } \\
\text { (Basis Points) }\end{array}$} \\
\hline \multirow[b]{2}{*}{ Bank Name } & \multicolumn{3}{|c|}{ Estimated Elasticities } & \multicolumn{2}{|c|}{2014} & \multicolumn{2}{|c|}{2015} & \multicolumn{2}{|c|}{2016} \\
\hline & $\begin{array}{c}\text { Funding Costs to } \\
\text { CET1 }\end{array}$ & $\begin{array}{c}\text { Funding Costs } \\
\text { to NII }\end{array}$ & $\begin{array}{c}\text { CET1 to Funding } \\
\text { Costs }\end{array}$ & $\begin{array}{l}\Delta \text { Funding } \\
\text { Costs }\end{array}$ & $\Delta$ CET1 & $\begin{array}{l}\Delta \text { Funding } \\
\text { Costs }\end{array}$ & $\Delta$ CET1 & $\begin{array}{l}\Delta \text { Funding } \\
\text { Costs }\end{array}$ & $\Delta$ CET1 \\
\hline Bank 1 & -1.048 & -0.547 & -0.320 & 213 & -68 & 296 & -95 & 308 & -99 \\
\hline Bank 2 & -1.048 & -0.547 & -0.320 & 103 & -33 & 87 & -28 & 116 & -37 \\
\hline Bank 3 & -1.048 & -0.547 & -0.320 & 311 & -99 & 310 & -99 & 557 & -178 \\
\hline Bank 4 & -1.048 & -0.547 & -0.320 & 88 & -28 & 96 & -31 & 98 & -31 \\
\hline Bank 5 & -1.048 & -0.547 & -0.320 & 225 & -72 & 91 & -29 & 3 & -1 \\
\hline Bank 6 & -1.048 & -0.547 & -0.320 & 178 & -57 & 159 & -51 & 107 & -34 \\
\hline Bank 7 & -1.048 & -0.547 & -0.320 & 335 & -107 & 167 & -53 & 153 & -49 \\
\hline Bank 8 & -1.048 & -0.547 & -0.320 & 59 & -19 & 86 & -28 & 69 & -22 \\
\hline Bank 9 & -1.048 & -0.547 & -0.320 & 595 & -191 & 858 & -275 & 976 & -312 \\
\hline Bank 10 & -1.048 & -0.547 & -0.320 & 243 & -78 & 351 & -112 & 506 & -162 \\
\hline Bank 11 & -1.048 & -0.547 & -0.320 & 93 & -30 & 10 & -3 & -42 & 13 \\
\hline $\begin{array}{l}\text { Source: Aut } \\
\text { Notes: This } \\
\text { adverse scena } \\
\text { constant asse }\end{array}$ & $\begin{array}{l}\text { ulations using EBA' } \\
\text { Ns the additional im } \\
\text { 2014-2016. The sam } \\
\text { r the stress test hor }\end{array}$ & $\begin{array}{l}\text { stress test result } \\
\text { ipact of the inte } \\
\text { izle of banks cov } \\
\text { izon under EBA' }\end{array}$ & $\begin{array}{l}\text { s and estimation re } \\
\text { action between fu } \\
\text { ers those banks inc } \\
\text { static balance she }\end{array}$ & $\begin{array}{l}\text { costs and solv } \\
\text { in the } 2014 \mathrm{E} \\
\text { umption. }\end{array}$ & $\begin{array}{l}\text { ency ratios } \\
\text { J-wide exer }\end{array}$ & $\begin{array}{l}\text { hk' commo } \\
\text { hich are als }\end{array}$ & $\begin{array}{l}\text { equity Tier } \\
\text { ncluded in }\end{array}$ & $\begin{array}{l}\text { T1) under EBA } \\
\text { sample. We as }\end{array}$ & 's \\
\hline
\end{tabular}


Figure 1. Cross-Sectional Distribution of Bank Solvency and Funding Costs

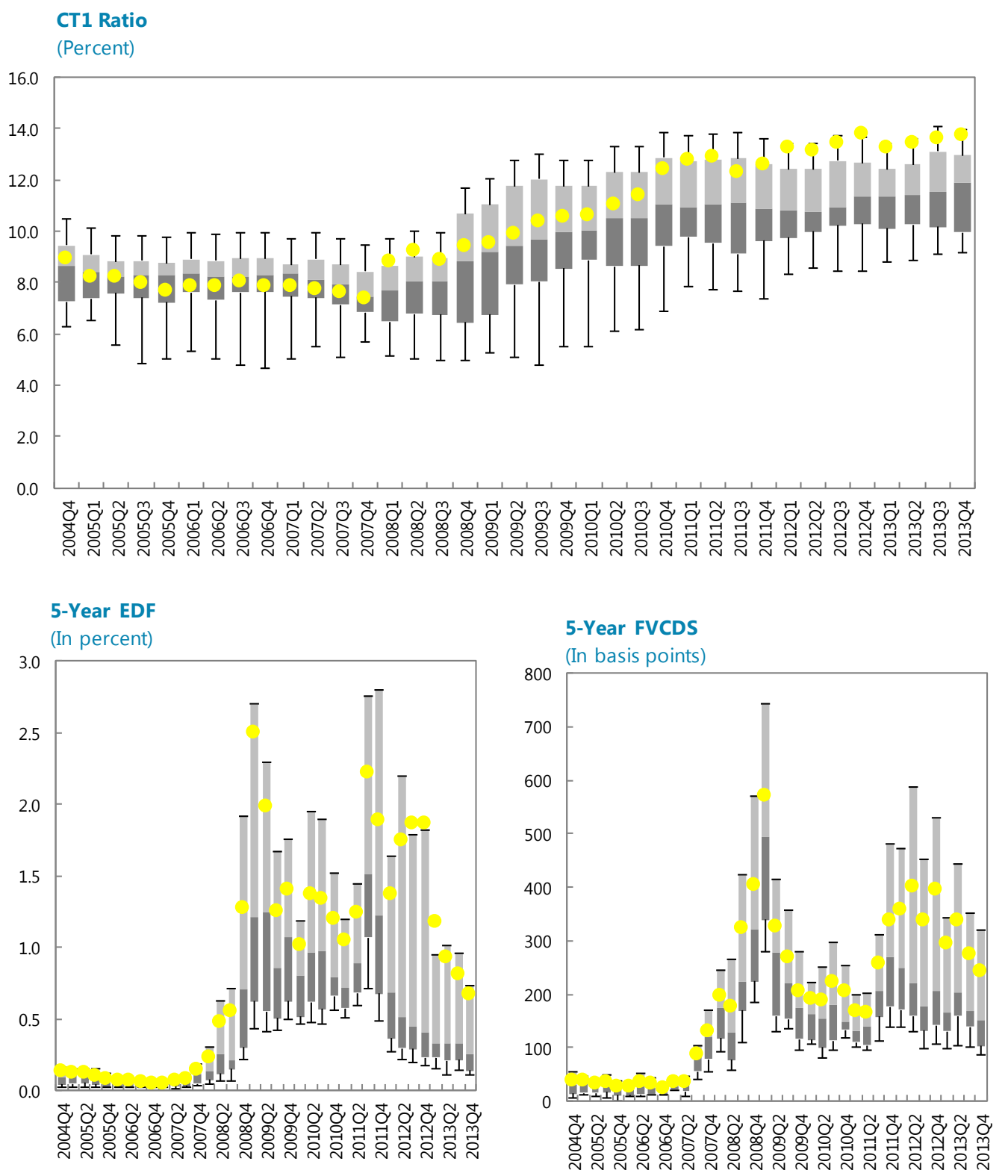

Note: Evolution of the distribution of regulatory capital measures and market-based indicator across time. Source: national supervisory data, and Moody's KMV. The top chart shows the distribution of bank core Tier 1 capital ratio (CT1). The bottom charts show the distribution of $5 y$ expected default frequency (EDF) and $5 y$ CDS spreads (CDS). The boxplots include the mean (yellow dot), the 25th and 75th percentiles (shaded areas) and the 10th and 90th percentiles (whiskers). 
Figure 2. Evolution of Bank Solvency and Funding Costs
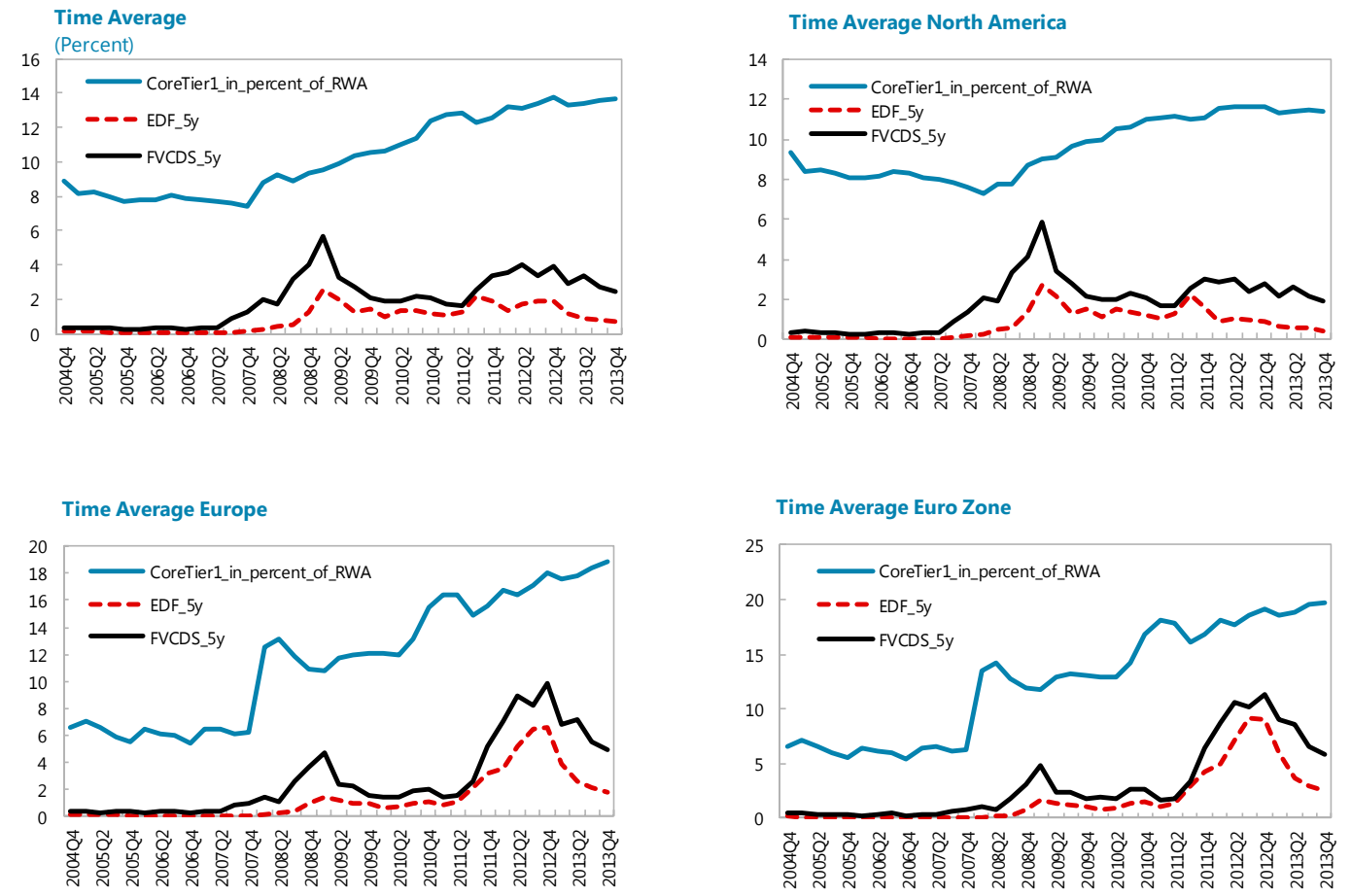

Notes: This panel shows the evolution of solvency ratios and funding costs for the sample of European and North American banks from 2004Q4 to 2013Q4. Source: national supervisory data, and Moody's KMV. The reason behind the jump in CT1 in the bottom charts in Q1 2008 is that the data for the CT1 ratios of the Dutch banks are reported from that time onwards and the average capital ratio of these banks is higher. 
Figure 3. Decomposition of Impact on CET1-2014 EBA Stress Test

Shock to CET1 ratio

(Basis points)

Solvency-funding nexus

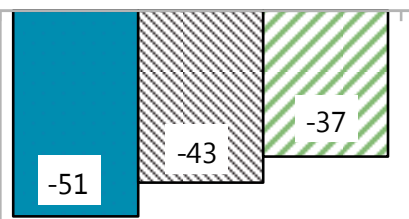

Overall effect
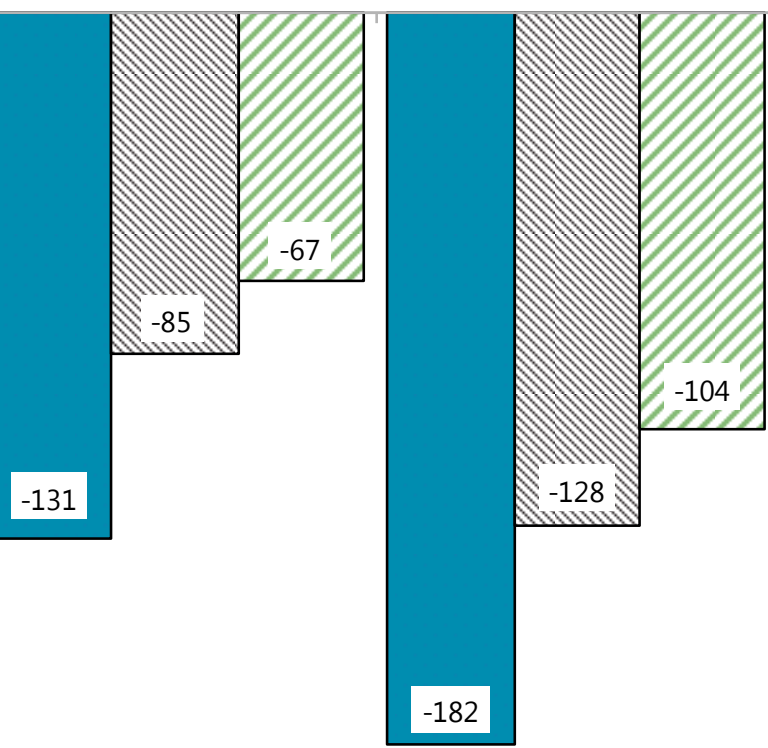

ㅁ2014 $\mathbf{Q} 2015 \square 2016$

Source: Author's calculations using EBA' stress test results and estimation results. 


\section{REFERENCES}

Acharya, V., and N. Mora (2015), “A Crisis of Banks as Liquidity Providers," Journal of Finance, 70 (1), 1-43.

Afonso, G., Kovner, A., and A. Schoar (2011), "Stressed, Not Frozen: The Federal Funds Market in the Financial Crisis," Journal of Finance, 66 (4), 1109-1139.

Annaert, J., M. De Ceuster, P. Van Roy and C. Vespro (2013), "What determines euro area bank CDS spread?” Journal of International Money and Finance 32, 444-461

Arellano, M. and S. Bond (1991), "Some tests of specification for panel data: Monte Carlo evidence and an application to employment equations," The Review of Economic Studies, 58(2), 277-297.

and O. Bover (1995), "Another look at the instrumental variable estimation of error-components models" Journal of Econometrics, 68 (1), 29-51.

Aymanns, C., Caceres, C., Daniel, C., and Schumacher, L., (2016), "Bank Solvency and Funding Costs". IMF Working Paper WP/16/64, Washington D.C.

Babihuga, Rita and Marco Spaltro (2014), "Bank Funding Costs for International Banks," IMF Working Paper, April 2014.

Bank of England (2014), Bank funding costs: what are they, what determines them and why do they matter? Quarterly Bulleting 2014 Q4.

Bhargava, A. (1991), Identification and panel data models with endogenous regressors. Review of Economic Studies, 58 (1), 129-140.

Basel Committee on Banking Supervision (2013a), "Liquidity stress testing: a survey of theory, empirics and current industry and supervisory practices," Working Paper 24.

(2013b), "Literature review of factors relating to liquidity stress - extended version," Working Paper 25.

(2015), "The interplay of accounting and regulation and its impact on bank behavior: Literature review," Working Paper 28.

Binder, M., Hsiao, C. and M. H. Pesaran (2005), "Estimation and inference in short panel vector autoregression with unit roots and cointegration," Econometric Theory, 21 (4), 795-837.

Chen, L., P. Collin-Dufresne and R.S. Goldstein (2009), "On the relation between the credit spread puzzle and the equity premium puzzle," Review of Financial Studies, 22 (9), 3367-3409. 
Choi, I. (2001), "Unit root tests for panel data," Journal of International Money and Finance, $20,249-272$.

Cetina, J. (2015), "Incorporating Liquidity Shocks and Feedbacks in Bank Stress Tests," OFR Brief Series, July.

Distinguin, I., Roulet, C. and A. Tarazi, (2013), "Bank Regulatory Capital and Liquidity: Evidence from US and European Publicly Traded Banks," Journal of Banking and Finance 37 (9), 3295-3317.

Ericsson, J., Jacobs, K., and Oviedo, R., (2009), “The determinants of credit default swap premia," Journal of Financial and Quantitative Analysis, 44 (2), 109-132.

European Banking Authority (2014a), "Methodological Note EU-Wide Stress Test 2014”. (2014b), “2014 EU-Wide Stress Test Results” at http://www.eba.europa.eu/riskanalysis-and-data/eu-wide-stress-testing/2014/results

Gorton, G. (2010), Slapped in the Face by the Invisible Hand, Oxford University Press.

Gray, D., Wehrhahn, R., and Savage, L. (2012), Israel: Technical Note on Stress Test of the Banking, Insurance, and Pension Sectors, IMF Country Report No. 12/88.

Hasan, I., Liu, L. and G. Zhang (2016), "The Determinants of Global Bank Credit-DefaultSwap Spreads," Journal of Financial Services Research (forthcoming).

Holtz-Eakin, D., Newey, W., \& Rosen, H. S. (1988), Estimating vector autoregressions with panel data. Econometrica, 56(6), 1371-1395.

Hull, J. A. White (2000), Valuing Credit Default Swaps I: No Counterparty Default Risk, Journal of Derivatives, 8 (1), 29-40

Kitamura, T., Muto, I., and Takei, I. (2015), "How do Japanese banks set loan interest rates? Estimating pass-through using bank-level data," Bank of Japan WP No. 15-E-6.

McElroy, M. B (1977), Goodness of Fit for Seemingly Unrelated Regressions. Journal of Econometrics, 6, 381-387.

Merton, R., C., (1974), “On the pricing of corporate debt: The risk structure of interest rates," Journal of Finance 29 (2), 449-470.

Moody's Analytics. 2012, Public Firm Expected Default Frequency (EDFTM) Credit Measures: Methodology, Performance, and Model Extensions. New York. 
Nakamura, A. and M. Nakamura (1981), "On the Relationships Among Several Specification Error Tests Presented by Durbin, Wu, and Hausman," Econometrica, 49 (6), 1583588.

Nickell, S. (1981), "Biases in dynamic models with fixed effects," Econometrica, 49(6), $1417-1426$.

Kiviet, F. (1986), "On the rigour of some misspecification tests for modelling dynamic, relationships", Review of Economic Studies, 53, 241-261.

Pierret, D. (2014), "Systemic risk and the solvency-liquidity nexus of banks," International Journal of Central Banking, 11 (3), 193-227.

Puhr, C. and S. W. Schmitz (2014), "A view from the top - the interaction between solvency and liquidity stress," Journal of Risk Management in Financial Institutions, 7 (1), 38 51.

Roodman, D. (2009a), "How to do xtabond2: An introduction to difference and system GMM in Stata," The Stata Journal, 9 (1), 86-136.

(2009b), "A note on the theme of too many instruments," Oxford Bulletin of Economics and Statistics, 71(1), 135-158.

Schmitz, S. W. (2013), The Impact of the Liquidity Coverage Ratio (LCR) on the Implementation of Monetary Policy. Economic Notes 42 (2), 135-170.

Sims, C. (1980), "Macroeconomic reality,” Econometrica, 48 (1), 1-48.

Shleifer, A., and Vishny, R. (2011), Fire Sales in Finance and Economics, Journal of Economic Perspectives, 25 (1), 29-48

Staiger, D., J. H. Stock (1997), "Instrumental Variables Regression with Weak Instruments," Econometrica, 65 (3), 557-586.

Sun, Z., Munves, D., and D. T. Hamilton (2012), "Public Firm Expected Default Frequency (EDF) Credit Measures: Methodology, Performance, and Model Extensions," Technical report, Moody's Analytics.

Tarashev, N (2008), “An empirical evaluation of structural credit risk models," International Journal of Central Banking, 4 (1), 1-53.

Valderrama, L., (2017), “An Agent-Based Model for Stress Testing,” IMF WP forthcoming.

Verbeek, M. (2012), A Guide to Modern Econometrics, John Wiley \& Sons, Ltd. 